\title{
Genomics and Pharmacogenomics of Schizophrenia
}

\author{
Ramón Cacabelos ${ }^{1,2}$ \& Rocío Martínez-Bouza ${ }^{1,2}$ \\ 1 EuroEspes Biomedical Research Center, 15165-Bergondo, Coruña, Spain \\ 2 EuroEspes Chair of Biotechnology and Genomics, Camilo José Cela University, Madrid, Spain
}

\author{
Keywords \\ CNS disorders; Genetics; Genomics; \\ Pharmacogenetics; Pharmacogenomics; \\ Schizophrenia. \\ Correspondence \\ Prof. Dr. Ramón Cacabelos, EuroEspes \\ Biomedical Research Center, Institute for CNS \\ Disorders and Genomic Medicine, \\ 15165-Bergondo, Coruña, Spain. \\ Tel.: +34-981-780505; \\ Fax: +34-981-780511; \\ E-mail: rcacabelos@euroespes.com
}

doi: 10.1111/j.1755-5949.2010.00187.x

\begin{abstract}
SUMMARY
Schizophrenia (SCZ) is among the most disabling of mental disorders. Several neurobiological hypotheses have been postulated as responsible for SCZ pathogenesis: polygenic/ multifactorial genomic defects, intrauterine and perinatal environment-genome interactions, neurodevelopmental defects, dopaminergic, cholinergic, serotonergic, gammaaminobutiric acid (GABAergic), neuropeptidergic and glutamatergic/N-Methyl-D-Aspartate (NMDA) dysfunctions, seasonal infection, neuroimmune dysfunction, and epigenetic dysregulation. SCZ has a heritability estimated at 60-90\%. Genetic studies in SCZ have revealed the presence of chromosome anomalies, copy number variants, multiple single-nucleotide polymorphisms of susceptibility distributed across the human genome, aberrant single nucleotide polymorphisms (SNPs) in microRNA genes, mitochondrial DNA mutations, and epigenetic phenomena. Pharmacogenetic studies of psychotropic drug response have focused on determining the relationship between variation in specific candidate genes and the positive and adverse effects of drug treatment. Approximately, $18 \%$ of neuroleptics are major substrates of CYP1A2 enzymes, $40 \%$ of CYP2D6, and $23 \%$ of CYP3A4; $24 \%$ of antidepressants are major substrates of CYP1A2 enzymes, 5\% of CYP2B6, 38\% of CYP2C19, $85 \%$ of CYP2D6, and $38 \%$ of CYP3A4; $7 \%$ of benzodiazepines are major substrates of CYP2C19 enzymes, $20 \%$ of CYP2D6, and $95 \%$ of CYP3A4. About $10-20 \%$ of Western populations are defective in genes of the CYP superfamily. Only $26 \%$ of Southern Europeans are pure extensive metabolizers for the trigenic cluster integrated by the CYP2D6+CYP2C19+CYP2C9 genes. The pharmacogenomic response of SCZ patients to conventional psychotropic drugs also depends on genetic variants associated with SCZ-related genes. Consequently, the incorporation of pharmacogenomic procedures both to drugs in development and drugs on the market would help to optimize therapeutics in SCZ and other central nervous system (CNS) disorders.
\end{abstract}

\section{Introduction}

Central nervous system (CNS) disorders are the third health problem in developed countries, representing $10-15 \%$ of deaths, after cardiovascular disorders (25-30\%) and cancer (20-25\%). Among mental disorders, schizophrenia (SCZ) is the most disabling disease in individuals during their productive life. In addition, there is an alarming abuse of inappropriate psychotropic drug consumption worldwide. Clinicians use concomitant antipsychotic therapy for management of psychotic disorders despite a paucity of evidence for this practice. Overall, concomitant antipsychotic therapy was documented in $9 \%$ of the visits in US outpatient settings involving antipsychotic agents, and monotherapy in $91 \%$ of the visits. The use of atypical agents (risperidone, olanzapine, quetiapine) was common in both forms of therapy. Concomitant therapy is frequently used for psychoses and bipolar disorder (BD), especially in patients 40-64 years old [1]. From 1996/1997 to 2002/2003, visits involving atypical and combination antipsychotics increased by $>150 \%$, and visits involving typical antipsychotics decreased by $71 \%$ [2]. With the use of concomitant antipsychotic therapy as a quality of care measure, there is a need to optimize prescribing of these potent combinations [1].

It seems clear that abuse, misuse, self-prescription, and uncontrolled medical prescription of psychotropic drugs are becoming a major problem with unpredictable consequences for brain health in the future. In parallel a growing body of fresh knowledge on the pathogenesis of CNS disorders, together with data on neurogenomics and pharmacogenomics is emerging in recent times. The incorporation of this new armamentarium of molecular pathology and genomic medicine to the daily medical practice, together with educational programs for the correct use of medication, must help to optimize therapeutics $[3,4]$. 
Drug metabolism, and the mechanisms underlying drug efficacy and safety, are genetically regulated complex traits in which hundreds of genes cooperatively participate. Disease-associated genomics, transcriptomics, proteomics, and metabolomics are essential components of the therapeutic outcome [5]. Pharmacogenomic factors may account for $60-90 \%$ of drug variability in drug disposition and pharmacodynamics. About $10-20 \%$ of Caucasians are carriers of defective CYP2D6 polymorphic variants, which alter the metabolism of many psychotropic agents. The incorporation of pharmacogenetic/pharmacogenomic protocols into CNS research and clinical practice can foster the optimization of therapeutics by helping to develop cost-effective pharmaceuticals and improving drug efficacy and safety [3-16].

\section{Pathogenic Theories}

SCZ and related disorders are highly heritable but cannot be explained by currently known genetic risk factors. SCZ has a heritability estimated at 60-90\%. Several neurobiological hypotheses have been postulated as responsible for SCZ pathogenesis: polygenic/multifactorial genomic defects, intrauterine and perinatal environment-genome interactions, neurodevelopmental defects, dopaminergic, cholinergic, serotonergic, gamma-aminobutyric acid (GABA) ergic, neuropeptidergic and glutamatergic/N-methylD-aspartate (NMDA) dysfunctions, seasonal infection, neuroimmune dysfunction, and epigenetic dysregulation. The dopamine hypothesis of SCZ has been one of the most enduring ideas in psychiatry. Initially, the emphasis was on a role of hyperdopaminergia in the etiology of SCZ, but it was subsequently reconceptualized to specify subcortical hyperdopaminergia with prefrontal hypodopaminergia [17]. Carlsson's hypothesis postulates that the positive and negative symptoms of SCZ are due to failure of mesolimbic and mesocortical projections consequent on hypofunction of the glutamate NMDA receptor [18]. While multiple theories have been put forth regarding the origin of SCZ, by far the vast majority of evidence points to the neurodevelopmental model in which developmental insults as early as late first or early second trimester lead to the activation of pathologic neural circuits during adolescence or young adulthood leading to the emergence of positive or negative symptoms [19]. Another important issue is the role of gender in SCZ. Sex differences in SCZ can be caused by the disease process itself, by genetic and hormonal differences, by differences in the maturation and morphology of the brain, and in age- and gender-specific behavioral patterns [20].

\section{Structural Genomics}

Genetic studies in SCZ have revealed the presence of cytogenetic changes, chromosome anomalies, copy-number variants (CNV), multiple single nucleotide polymorphisms (SNPs) of susceptibility (Table 1), aberrant SNPs in microRNA (miRNA) genes, mitochondrial DNA (mtDNA) mutations, and epigenetic phenomena [21]. First-degree relatives of probands with SCZ or BD are at increased risk of these disorders. Heritability for SCZ and BD is 64 and 59, respectively. Shared environmental effects are small but substan- tial for both disorders (SCZ: 4.5\%; BD: $3.4 \%$ ). SCZ and BD partly share common genetic determinants [22].

Polymorphic variants in top 30 genes associated with SCZ at SZGene are listed in Table 2 [3,15,23]. A selective number of genes (or pathological pathways) with potential effect in SCZ pathogenesis include the following (in alphabetical order)(Table 1):

\section{ABCA13 (ATP-Binding Cassette, Subfamily A [ABC1], Member 13)}

The lipid transporter gene $A B C A 13$ is a susceptibility factor for both SCZ and BD. Multiple rare coding variants were identified including one nonsense and nine missense mutations and compound heterozygosity/homozygosity in $6 \%$ of cases. The population attributable risk of these mutations was $2.2 \%$ for SCZ and $4.0 \%$ for BD [24].

\section{Abelson Helper Integration Site 1 (AHI1)}

The AHI1 gene locus on chromosome 6q23 is among a group of candidate loci for SCZ susceptibility. The region contains two genes, AHI1 and C6orf217. Both genes and the neighboring phosphodiesterase 7B (PDE7B) may be considered candidates for involvement in the genetic etiology of SCZ [25]. Of 14 SNPs tested (ATP2B2, HS3ST2, UNC5C, BAG3, PDE7B, PAICS, PTGFRN, NR3C2, ZBTB20, ST6GAL2, PIP5K1B, EPHA6, KCNH5, and AJAP1), only one (rs9389370) in $P D E 7 B$ showed significant evidence for association with SCZ [26].

\section{Adenylosuccinate Synthase (ADSS) and Ataxia Telangiectasia (ATM) Genes}

The blood-derived RNA levels of the ADSS and ATM genes were found to be down- and up-regulated, respectively, in schizophrenics compared with controls. ADSS catalyzes the first committed step of adenosine monophosphate (AMP) synthesis, while ATM kinase serves as a key signal transducer in the DNA double-strand breaks response pathway. Studies with 6 SNPs in the ADSS gene and 3 SNPs in the ATM gene did not show significant difference in the genotype, allele, or haplotype distributions in a Chinese population of SCZ patients. Interactions among rs3102460 in the ADSS gene and rs227061 and rs664143 in the ATM gene revealed a significant association with SCZ with a maximum testing accuracy of $60.4 \%$ [27].

\section{Cholesterol Transport Genes}

Several studies suggest an accumulation of APOE-4 allele in SCZ [6]. Disturbances in lipid homeostasis and myelination have been proposed in the pathophysiology of SCZ and BD. Several antipsychotic and antidepressant drugs increase lipid biosynthesis through activation of the Sterol Regulatory Element-Binding Protein (SREBP) transcription factors, which control the expression of numerous genes involved in fatty acid and cholesterol biosynthesis. Significant transcriptional changes of cholesterol transport genes (APOE, ABCA1, NPC1, NPC2, NPC1L1), which are 
Table 1. Genes associated with schizophrenia and psychosis $[15,159,160]$

\begin{tabular}{|c|c|c|c|c|}
\hline Locus & Symbol & Aliases & Title & OMIM \\
\hline 1cen-q12 & ADSS & ADEH, MGC20404 & Adenylosuccinate synthase & 103060 \\
\hline $1 p$ & SCZD12 & & schizophrenia 12 & 608543 \\
\hline $1 \mathrm{p} 13.3$ & GSTM1 & $\begin{array}{l}\text { GST1, GSTM1-1, GSTM1a-1a, GSTM1b-1b, } \\
\text { GTH4, GTM1, H-B, MGC26563, MU, } \\
\text { MU-1 }\end{array}$ & Glutathione S-transferase mu 1 & 138350 \\
\hline $1 q 23-q 25$ & FMO3 & FMOII, MGC34400, TMAU, dJ127D3.1 & Flavin containing monooxygenase 3 & 136132 \\
\hline $1 \mathrm{p} 31$ & LEPR & CD295, OBR & Leptin receptor & 601007 \\
\hline $1 \mathrm{p} 31$ & PDE4B & $\begin{array}{l}\text { RP5-876C12.1, DKFZP686F2182, DPDE4, } \\
\text { MGC126529, PDE4B5, PDEIVB }\end{array}$ & $\begin{array}{l}\text { Phosphodiesterase 4B, camp-specific } \\
\text { (phosphodiesterase E4 dunce homolog, } \\
\text { drosophila) }\end{array}$ & 600127 \\
\hline $1 \mathrm{p} 33$ & SLC6A9 & DKFZp547A1118, GLYT1 & $\begin{array}{l}\text { Solute carrier family } 6 \text { (neurotransmitter } \\
\text { transporter, glycine), member } 9\end{array}$ & 601019 \\
\hline 1p34-p33 & GRIK3 & EAA5, GLR7, GLUR7, GluR7a & Glutamate receptor, ionotropic, kainate 3 & 138243 \\
\hline $1 \mathrm{p} 36.3$ & MTHFR & & $\begin{array}{l}\text { 5,10-methylenetetrahydrofolate } \\
\text { reductase (nadph) }\end{array}$ & 607093 \\
\hline 1 p36.11 & CNR2 & $R P 11-4 M 23.1, C B 2, C X 5$ & Cannabinoid receptor 2 (macrophage) & 605051 \\
\hline $1 q 21$ & CTSK & $\begin{array}{l}\text { RP11-363122.4, CTSO2, CTSO, CTSO1, } \\
\text { CTSO2, MGC23107, PKND, PYCD }\end{array}$ & Cathepsin K & 601105 \\
\hline $1 q 21-q 22$ & SELENBP1 & $\begin{array}{l}\text { RP11-126K1.7, FLJ13813, LPSB, SP56, } \\
\text { hSBP, hSP56 }\end{array}$ & Selenium binding protein 1 & 604188 \\
\hline $1 q 21-q 23$ & $C R P$ & MGC149895, MGC88244, PTX1 & c-Reactive protein, pentraxin-related & 123260 \\
\hline $1 q 23.3$ & RGS4 & $\begin{array}{l}\text { RP11-430G6.1, DKFZp761F1924, } \\
\text { MGC2124, MGC60244, RGP4, SCZD9 }\end{array}$ & Regulator of G-protein signaling 4 & 602516 \\
\hline $1 \mathrm{q} 25.1$ & PRDX6 & $\begin{array}{l}\text { 1-Cys, AOP2, KIAA0106, MGC46173, } \\
\text { NSGPX, PRX, aiPLA2, p29 }\end{array}$ & Peroxiredoxin 6 & 602316 \\
\hline $1 q 31-q 42$ & PSEN2 & $A D 3 L, A D 4, P S 2, S T M 2$ & Presenilin 2 (alzheimer disease 4) & 600759 \\
\hline $1 q 31-q 32$ & IL10 & $\begin{array}{l}\text { CSIF, IL-10, IL10A, MGC126450, } \\
\quad \text { MGC126451, TGIF }\end{array}$ & Interleukin 10 & 124092 \\
\hline $1 q 32$ & $A V P R 1 B$ & AVPR3 & Arginine vasopressin receptor $1 \mathrm{~B}$ & 600264 \\
\hline $1 q 32.1$ & CHI3L1 & $\begin{array}{l}\text { ASRT7, DKFZp686N19119, FLJ38139, } \\
\text { GP39, HC-gp39, HCGP-3P, YKL40, } \\
\text { YYL-40 }\end{array}$ & $\begin{array}{l}\text { Chitinase 3-like } 1 \text { (cartilage } \\
\text { glycoprotein-39) }\end{array}$ & 601525 \\
\hline $1 q 32.2$ & PLXNA2 & $\begin{array}{l}\text { RP11-328D5.3, FLJ11751, FLJ30634, } \\
\quad \text { KIAA0463, OCT, PLXN2 }\end{array}$ & Plexin A2 & 601054 \\
\hline $1 q 42.1$ & DISC1 & $\begin{array}{l}\text { RP4-730B13.1, C10rf136, FLJ13381, } \\
\text { FLJ21640, FLJ25311, FLJ41105, } \\
\text { KIAA0457, SCZD9 }\end{array}$ & Disrupted in schizophrenia 1 & $605210 / 181500$ \\
\hline $1 q 42.1$ & DISC2 & DISC1OS; NCRNA00015 & Disrupted in schizophrenia 2 & $606271 / 181500$ \\
\hline $1 q 42.1$ & TSNAX & DISC1, TRAX & Translin-associated factor $x$ & 602964 \\
\hline $2 \mathrm{p} 16.3$ & NRXN1 & $\begin{array}{l}\text { DKFZp313P2036, FLJ35941, Hs.22998, } \\
\text { KIAA0578 }\end{array}$ & Neurexin 1 & 600565 \\
\hline $2 q 14$ & IL1B & IL-1, IL1-BETA, IL1F2 & Interleukin 1 , beta & 147720 \\
\hline $2 q 14.2$ & IL1RN & $\begin{array}{l}\text { DIRA, ICIL-1RA, IL-1ra3, IL1F3, IL1RA, IRAP, } \\
\quad \text { MGC10430, MVCD4 }\end{array}$ & Interleukin 1 receptor antagonist & 147679 \\
\hline $2 q 31$ & GAD1 & FLJ45882, GAD, SCP & Glutamate decarboxylase 1 (brain, 67kDa) & 605363 \\
\hline $2 q 32.1$ & ZNF804A & C2orf10 & Zinc finger protein 804A & 612282 \\
\hline $2 q 32.3-q 33$ & GULP1 & CED-6, CED6, FLJ31156, GULP & $\begin{array}{l}\text { GULP, engulfment adaptor PTB domain } \\
\text { containing } 1\end{array}$ & 608165 \\
\hline $2 q 33.3-q 34$ & ERBB4 & HER4, MGC138404, p180erbB4 & $\begin{array}{l}\text { v-Erb-a erythroblastic leukemia viral } \\
\text { oncogene homolog } 4 \text { (avian) }\end{array}$ & 600543 \\
\hline $3 p 21.2$ & GRM2 & GLUR2, GPRC1B, MGLUR2, mGlu2 & Glutamate receptor, metabotropic 2 & 604099 \\
\hline $3 p 21.3$ & LARS2 & KIAA0028, LEURS, MGC26121 & leucyl-tRNA synthetase 2, mitochondrial & 604544 \\
\hline $3 p 22-p 21.3$ & CCK & MGC117187 & Cholecystokinin & 118440 \\
\hline $3 p 25$ & OXTR & OT-R & Oxytocin receptor & 167055 \\
\hline $3 p 25$ & PPARG & $\begin{array}{l}\text { CIMT1, GLM1, NR1C3, PPARG1, PPARG2, } \\
\text { PPARgamma }\end{array}$ & $\begin{array}{l}\text { Peroxisome proliferator-activated } \\
\text { receptor gamma }\end{array}$ & 601487 \\
\hline $3 p 25$ & SYN2 & SYNII, SYNIIa, SYNIIb & Synapsin II & 600755 \\
\hline
\end{tabular}


Table 1. Continued

\begin{tabular}{|c|c|c|c|c|}
\hline Locus & Symbol & Aliases & Title & OMIM \\
\hline 3p26.1-p25.1 & GRM7 & $\begin{array}{l}\text { FLJ40498, GLUR7, GPRC1G, MGLU7, } \\
\text { MGLUR7 }\end{array}$ & Glutamate receptor, metabotropic 7 & 604101 \\
\hline $3 q 13.3$ & DRD3 & $\begin{array}{l}\text { D3DR, ETM1, FET1, MGC149204, } \\
\text { MGC149205 }\end{array}$ & Dopamine receptor D3 & 126451 \\
\hline $3 q 13.3$ & GSK3B & & Glycogen synthase kinase 3 beta & 605004 \\
\hline $4 p 15.2$ & PI4K2B & FLJ11105, PI4KIIB, PIK42B & Phosphatidylinositol 4-kinase type 2 beta & 612101 \\
\hline $4 q 12$ & CLOCK & KAT13D, KIAA0334, bHLHe8 & Clock homolog (mouse) & 601851 \\
\hline $4 q 31-q 32$ & TDO2 & TDO, TPH2, TRPO & Tryptophan 2,3-dioxygenase & 191070 \\
\hline $5 p 15.3$ & SLC6A3 & $D A T, D A T 1$ & $\begin{array}{l}\text { Solute carrier family } 6 \text { (neurotransmitter } \\
\text { transporter, dopamine), member } 3\end{array}$ & 126455 \\
\hline $5 q 11.2-q 13$ & HTR1A & 5-HT1A, 5HT1a, ADRB2RL1, ADRBRL1 & $\begin{array}{l}\text { 5-Hydroxytryptamine (serotonin) receptor } \\
1 \mathrm{~A}\end{array}$ & 109760 \\
\hline $5 q 11.2-q 13.3$ & SCZD1 & & $\begin{array}{l}\text { Schizophrenia susceptibility locus/chr. } \\
\text { 5q-related }\end{array}$ & $181510 / 181500$ \\
\hline $5 q 12$ & PDE4D & $\begin{array}{l}\text { DKFZP686M11213, DPDE3, FLJ97311, } \\
\text { HSPDE4D, PDE4DN2, STRK1 }\end{array}$ & $\begin{array}{l}\text { Phosphodiesterase 4D, camp-specific } \\
\text { (phosphodiesterase E3 dunce homolog, } \\
\text { drosophila) }\end{array}$ & 600129 \\
\hline $5 q 31$ & PCDH12 & VE-cadherin-2, VECAD2 & Protocadherin 12 & 605622 \\
\hline $5 q 33$ & MEGF10 & DKFZp781K1852, FLJ41574, KIAA1780 & Multiple EGF-like-domains 10 & 612453 \\
\hline $5 q 34$ & GABRB2 & MGC119386, MGC119388, MGC119389 & $\begin{array}{l}\text { Gamma-aminobutyric acid (GABA) A } \\
\text { receptor, beta } 2\end{array}$ & 600232 \\
\hline $5 q 35.1$ & DRD1 & $D A D R, D R D 1 A$ & Dopamine receptor D1 & 126449 \\
\hline $6 p 12$ & VEGFA & $\begin{array}{l}\text { RP1-261G23.1, MGC70609, MVCD1, } \\
\text { VEGF, VEGF-A, VPF }\end{array}$ & Vascular endothelial growth factor a & 192240 \\
\hline $6 p 21.3$ & GRM4 & GPRC1D, MGC177594, MGLUR4, mGlu4 & Glutamate receptor, metabotropic, 4 & 604100 \\
\hline $6 p 21.3$ & $H L A-D Q A 1$ & $\begin{array}{l}\text { CD, CELIAC1, DQ-A1, FLJ27088, FLJ27328, } \\
\text { GSE, HLA-DQA, MGC149527 }\end{array}$ & $\begin{array}{l}\text { Major histocompatibility complex, class II, } \\
\text { DQ alpha } 1\end{array}$ & 146880 \\
\hline $6 p 21.3$ & $H L A-E$ & $\begin{array}{r}\text { DAMA-277114.1, DKFZp686P19218, } \\
\text { EA1.2, EA2.1, HLA-6.2, MHC, QA1 }\end{array}$ & $\begin{array}{l}\text { Major histocompatibility complex, class I, } \\
\text { E }\end{array}$ & 143010 \\
\hline $6 p 21.3$ & SYNGAP1 & $\begin{array}{l}\text { DASS-97D12.6, DKFZP761G1421, } \\
\text { KIAA1938, MRD5, RASA1, RASA5, } \\
\text { SYNGAP }\end{array}$ & $\begin{array}{l}\text { Synaptic Ras GTPase activating protein } 1 \\
\text { homolog (rat) }\end{array}$ & 603384 \\
\hline $6 p 21.3$ & TAP1 & $\begin{array}{l}\text { DAAP-57C1.5, ABC17, ABCB2, APT1, } \\
\text { D6S114E, FLJ26666, FLJ41500, PSF1, } \\
\text { RING4, TAP1*0102N, TAP1N }\end{array}$ & $\begin{array}{l}\text { Transporter 1, ATP-binding cassette, } \\
\text { subfamily b (MDR/TAP) }\end{array}$ & 170260 \\
\hline $6 p 22.1$ & MOG & DAQB-92E24.2, MGC26137, MOGIG2 & Myelin oligodendrocyte glycoprotein & 159465 \\
\hline $6 p 22.3$ & DTNBP1 & $\begin{array}{l}\text { RP1-147M19.1, DBND, DKFZp564K192, } \\
\text { FLJ30031, HPS7, MGC20210, My031, } \\
\text { SDY }\end{array}$ & Dystrobrevin-binding protein 1 (dysbindin) & 607145 \\
\hline 6p24-p22 & SCZD3 & & $\begin{array}{l}\text { Schizophrenia susceptibility locus/chr. } \\
6 p \text {-related }\end{array}$ & $600511 / 181500$ \\
\hline 6p24-p23 & JARID2 & $J M J$ & Jumonji, AT rich interactive domain 2 & 601594 \\
\hline 6p25.1-p24.3 & MUTED & DKFZp686E2287, MU & Muted homolog (mouse) & 607289 \\
\hline $6 q 13-q 26$ & SCZD5 & & $\begin{array}{l}\text { Schizophrenia susceptibility locus/chr. } \\
\text { 6q-related }\end{array}$ & $603175 / 181500$ \\
\hline $6 q 16$ & MCHR2 & GPR145, MCH2, MCH2R, SLT & $\begin{array}{l}\text { Melanin-concentrating hormone receptor } \\
2\end{array}$ & 606111 \\
\hline $6 \mathrm{p} 21.2$ & DAAM2 & $\begin{array}{l}\text { RP1-278E11.1, KIAA0381, MGC90515, } \\
\text { dJ90A20A.1 }\end{array}$ & $\begin{array}{l}\text { Dishevelled associated activator of } \\
\text { morphogenesis } 2\end{array}$ & 606627 \\
\hline $6 \mathrm{q} 21$ & FYN & RP1-66H14.1, MGC45350, SLK, SYN & FYN oncogene related to SRC, FGR, YES & 137025 \\
\hline $6 q 21.3$ & HSPA1B & $\begin{array}{l}\text { DAAP-21F2.7, FLJ54328, HSP70-1B, } \\
\text { HSP70-2, HSPA1A }\end{array}$ & Heat shock 70kDa protein 1B & 603012 \\
\hline $6 q 22-q 23$ & FABP7 & $\begin{array}{l}\text { B-FABP, BLBP, DKFZp547J2313, FABPB, } \\
\quad M R G\end{array}$ & Fatty acid binding protein 7 , brain & 602965 \\
\hline $6 q 23.1$ & STX7 & $R P 11-560121.1$ & Syntaxin 7 & 603217 \\
\hline $6 q 23.2$ & TAAR6 & RP11-295F4.3, SCZD5, TA4, TRAR4 & Trace amine associated receptor 6 & 608923 \\
\hline $6 q 23-q 24$ & PDE7B & MGC88256; bA472E5.1; PDE7B & Phosphodiesterase 7B & \\
\hline
\end{tabular}


Table 1. Continued

\begin{tabular}{|c|c|c|c|c|}
\hline Locus & Symbol & Aliases & Title & OMIM \\
\hline $6 q 27$ & TBP & $\begin{array}{l}\text { GTF2D, GTF2D1, MGC117320, } \\
\text { MGC126054, MGC126055, SCA17, TFIID }\end{array}$ & TATA box binding protein & 600075 \\
\hline $6 q 26-q 27$ & QKI & DKFZp58610923, Hqk, QK, QK1, QK3 & $\begin{array}{l}\text { Quaking homolog, KH domain RNA } \\
\text { binding (mouse) }\end{array}$ & 609590 \\
\hline $7 p 12.3$ & $A B C A 13$ & $\begin{array}{l}\text { FLJ16398; FLJ33876; FLJ33951; } \\
\text { DKFZp313D2411; ABCA13 }\end{array}$ & $\begin{array}{l}\text { ATP-binding cassette, subfamily A (ABC1), } \\
\text { member } 13\end{array}$ & 607807 \\
\hline $7 p 13$ & NPC1L1 & NPC11L1 & $\begin{array}{l}\text { NPC1 (Niemann-Pick disease, type C1, } \\
\text { gene)-like } 1\end{array}$ & 608010 \\
\hline $7 p 15.3$ & SP4 & HF1B, MGC130008, MGC130009, SPR-1 & SP4 transcription factor & 600540 \\
\hline $7 q 21.1$ & CYP3A4 & $\begin{array}{l}\text { CP33, CP34, CYP3A, CYP3A3, HLP, } \\
\text { MGC126680, NF-25, P450C3, P450PCN1 }\end{array}$ & $\begin{array}{l}\text { Cytochrome p } 450 \text {, family } 3 \text {, subfamily a, } \\
\text { polypeptide } 4\end{array}$ & 124010 \\
\hline $7 q 21.1$ & СYР3А5 & CP35, P450PCN3, PCN3 & $\begin{array}{l}\text { Cytochrome p } 450 \text {, family } 3 \text {, subfamily a, } \\
\text { polypeptide } 5\end{array}$ & 605325 \\
\hline $7 q 21.1-q 21.2$ & GRM3 & GLUR3, GPRC1C, MGLUR3, mGlu3 & Glutamate receptor, metabotropic-3 & 601115 \\
\hline $7 q 22$ & RELN & PRO1598, RL & Reelin & 600514 \\
\hline $7 q 31.3$ & LEP & FLJ94114, OB, OBS & Leptin & 164160 \\
\hline $7 q 31.1-q 31.2$ & NRCAM & KIAA0343, MGC138845, MGC138846 & Neuronal cell adhesion molecule & 601581 \\
\hline $7 q 32.3-q 33$ & $D G K I$ & DGK-IOTA & Diacylglycerol kinase, iota & 604072 \\
\hline $7 q 35-q 36$ & $\mathrm{KCNH} 2$ & ERG1, HERG, HERG1, KV11.1, LQT2, SQT1 & $\begin{array}{l}\text { Potassium voltage-gated channel, } \\
\text { subfamily h (eag-related), member } 2\end{array}$ & 152427 \\
\hline $7 q 35-q 36$ & CNTNAP2 & $\begin{array}{l}\text { AUTS15, CASPR2, CDFE, DKFZp781D1846, } \\
\text { NRXN4 }\end{array}$ & Contactin associated protein-like 2 & 604569 \\
\hline $8 p 11.2$ & CHRNB3 & & Cholinergic receptor, nicotinic, beta 3 & 118508 \\
\hline 8p11.2-p11.1 & DKK4 & DKK-4, MGC129562, MGC129563 & Dickkopf homolog 4 (Xenopus laevis) & 605417 \\
\hline 8p11.2-p11.1 & FGFR1 & $\begin{array}{l}\text { CEK; FLG; OGD; FLT2; KAL2; BFGFR; CD331; } \\
\quad \text { FGFBR; HBGFR; N-SAM; FLJ99988; } \\
\quad \text { FGFR1 }\end{array}$ & Fibroblast growth factor receptor 1 & 136350 \\
\hline $8 p 11.21$ & CHRNA6 & & Cholinergic receptor, nicotinic, alpha 6 & 606888 \\
\hline $8 p 12$ & PLAT & DKFZp686103148, T-PA, TPA & Plasminogen activator, tissue & 173370 \\
\hline $8 p 12$ & NRG1 & $\begin{array}{l}\text { ARIA, GGF, GGF2, HGL, HRG, HRG1, HRGA, } \\
\quad N D F, \text { SMDF }\end{array}$ & Neuregulin 1 & 142445 \\
\hline 8p12-p11.1 & SFRP1 & $F R P, F R P-1, F R P 1, F r Z A, S A R P 2$ & Secreted frizzled-related protein 1 & 604156 \\
\hline $8 p 21$ & CHRNA2 & & $\begin{array}{l}\text { Cholinergic receptor, nicotinic, alpha } 2 \\
\text { (neuronal) }\end{array}$ & 118502 \\
\hline $8 p 21$ & FGF17 & fibroblast growth factor 17 & Fibroblast growth factor 17 & 603725 \\
\hline $8 p 21$ & FZD3 & $z-3, h F z 3$ & Frizzled homolog of, 3 (Drosophila) & 606143 \\
\hline $8 p 21$ & NEFM & NEF3, NF-M, NFM & Neurofilament, medium polypeptide & 162250 \\
\hline $8 p 21$ & SCZD6 & & $\begin{array}{l}\text { Schizophrenia susceptibility locus/chr. } \\
\text { 8p-related }\end{array}$ & $603013 / 181500$ \\
\hline 8p21-p11.2 & ADRA1A & ADRA1C, ADRA1L1, ALPHA1AAR & Adrenergic, alpha-1A-, receptor & 104221 \\
\hline $8 p 21.3$ & PPP3CC & CALNA3, CNA3 & $\begin{array}{l}\text { Protein phosphatase } 3 \text { (formerly } 2 \mathrm{~B} \text { ), } \\
\text { catalytic subunit, gamma isoform }\end{array}$ & 114107 \\
\hline $8 p 21.3$ & SLC18A1 & CGAT, VAT1, VMAT1 & $\begin{array}{l}\text { Solute carrier family } 18 \text { (vesicular } \\
\text { monoamine), member } 1\end{array}$ & 193002 \\
\hline $8 p 22$ & NAT2 & $A A C 2$, PNAT & $\begin{array}{l}\mathrm{N} \text {-acetyltransferase } 2 \text { (arylamine } \\
\mathrm{N} \text {-acetyltransferase) }\end{array}$ & 612182 \\
\hline $8 p 22-p 21$ & DPYSL2 & CRMP2, DHPRP2, DRP-2, DRP2 & Dihydropyrimidinase-like 2 & 602463 \\
\hline $8 p 22-p 21.3$ & FGF20 & & Fibroblast growth factor 20 & 605558 \\
\hline $8 p 22-p 21.3$ & PCM1 & PTC4 & Pericentriolar material 1 & 600299 \\
\hline $8 p 23$ & ARHGEF10 & DKFZp686H0726, GEF10, MGC131664 & $\begin{array}{l}\text { Rho guanine nucleotide exchange factor } \\
\text { (GEF) } 10\end{array}$ & 608123 \\
\hline $8 p 23-p 21$ & EGR3 & MGC138484, PILOT & Early growth response 3 & 602419 \\
\hline $9 p 13.3$ & SIGMAR1 & $\begin{array}{l}\text { RP11-443P11.3, FLJ25585, MGC3851, } \\
\text { OPRS1, SR-BP1, SRBP }\end{array}$ & Sigma non-opioid intracellular receptor 1 & 601978 \\
\hline $9 p 24$ & SLC1A1 & RP11-6J24.1, EAAC1, EAAT3 & $\begin{array}{l}\text { Solute carrier family } 1 \text { (neuronal/epithelial } \\
\text { high affinity glutamate transporter, } \\
\text { system Xag), member } 1\end{array}$ & 133550 \\
\hline
\end{tabular}


Table 1. Continued

\begin{tabular}{|c|c|c|c|c|}
\hline Locus & Symbol & Aliases & Title & OMIM \\
\hline $9 p 22.3$ & SMARCA2 & $\begin{array}{l}\text { BAF190, BRM, FLJ36757, MGC74511, } \\
\text { SNF2, SNF2L2, SNF2LA, SWI2, Sth1p, } \\
\text { hBRM, hSNF2a }\end{array}$ & $\begin{array}{l}\text { SWI/SNF-related, matrix-associated, } \\
\text { actin-dependent regulator of } \\
\text { chromatin, subfamily a, member } 2\end{array}$ & 600014 \\
\hline $9 q 31.1$ & $A B C A 1$ & $\begin{array}{l}\text { ABC-1, ABC1, CERP, FLJ14958, HDLDT1, } \\
\text { MGC164864, MGC165011, TGD }\end{array}$ & $\begin{array}{l}\text { ATP-binding cassette, sub-family A } \\
\text { (ABC1), member } 1\end{array}$ & 600046 \\
\hline $9 q 34$ & CACNA1B & BIII, CACNL1A5, CACNN, Cav2.2 & $\begin{array}{l}\text { Calcium channel, voltage-dependent, N } \\
\text { type, alpha 1B subunit }\end{array}$ & 601012 \\
\hline $9 q 34.3$ & GRIN1 & NMDA1, NMDAR1, NR1 & $\begin{array}{l}\text { Glutamate receptor, ionotropic, N-methyl } \\
\text { D-aspartate } 1\end{array}$ & 138249 \\
\hline $10 q 22$ & GRID1 & RP11-93H12.1, KIAA1220 & Glutamate receptor, ionotropic, delta 1 & 610659 \\
\hline $10 q 24$ & $L G / 1$ & EPITEMPIN, EPT, ETL1, IB1099 & Leucine-rich, glioma inactivated 1 & 604619 \\
\hline $10 q 22.3$ & SCZD11 & & $\begin{array}{l}\text { Schizophrenia susceptibility locus, } \\
\text { chromosome } 10 \text { q-related }\end{array}$ & 608078 \\
\hline $10 q 22-q 23$ & NRG3 & HRG3, pro-NRG3 & Neuregulin 3 & 605533 \\
\hline $11 \mathrm{p} 11.2$ & FOLH1 & $\begin{array}{l}\text { FGCP, FOLH, GCP2, GCPII, NAALAD1, } \\
\text { NAALAdase, PSM, PSMA, mGCP }\end{array}$ & $\begin{array}{l}\text { Folate hydrolase (prostate-specific } \\
\text { membrane antigen) } 1\end{array}$ & 600934 \\
\hline $11 \mathrm{p} 13$ & $B D N F$ & MGC34632 & Brain-derived neurotrophic factor & 113505 \\
\hline 11p15.3-p14 & TPH1 & MGC119994, TPRH, TRPH & Tryptophan hydroxylase 1 & 191060 \\
\hline $11 p 15.5$ & DRD4 & $D 4 D R$ & Dopamine receptor D4 & 126452 \\
\hline $11 q 12-q 13.1$ & FADS2 & $\begin{array}{l}\text { D6D, DES6, FADSD6, LLCDL2, SLL0262, } \\
\text { TU13 }\end{array}$ & Fatty acid desaturase 2 & 606149 \\
\hline $11 q 13$ & GSTP1 & DFN7, FAEES3, GST3, GSTP, PI & Glutathione S-transferase pi 1 & 134660 \\
\hline $11 q 14-q 21$ & SCZD2 & & $\begin{array}{l}\text { Schizophrenia susceptibility locus/chr. } \\
\text { 11-related }\end{array}$ & $603342 / 181500$ \\
\hline $11 q 22.3$ & GRIK4 & EAA1, GRIK, KA1 & Glutamate receptor, ionotropic, kainate 4 & 600282 \\
\hline $11 q 22.3$ & MMP3 & $\begin{array}{l}\text { CHDS6, MGC126102, MGC126103, } \\
\text { MGC126104, MMP-3, SL-1, STMY, } \\
\text { STMY1, STR1 }\end{array}$ & $\begin{array}{l}\text { Matrix metallopeptidase } 3 \text { (stromelysin } 1 \text {, } \\
\text { progelatinase) }\end{array}$ & 185250 \\
\hline $11 q 22-q 23$ & ATM & $\begin{array}{l}\text { AT1, ATA, ATC, ATD, ATDC, ATE, } \\
\text { DKFZP781A0353, MGC74674, TEL1, } \\
\text { TELO1 }\end{array}$ & Ataxia telangiectasia mutated & 607585 \\
\hline $11 q 23$ & DRD2 & $D 2 D R, D 2 R$ & Dopamine receptor D2 & 126450 \\
\hline $11 q 23.1$ & NCAM1 & CD56, MSK39, NCAM & Neural cell adhesion molecule 1 & 116930 \\
\hline $11 q 24$ & NRGN & $R C 3$, hng & $\begin{array}{l}\text { Neurogranin (protein kinase C substrate, } \\
\text { RC3) }\end{array}$ & 602350 \\
\hline $11 q 25$ & OPCML & IGLON1, OBCAM, OPCM & $\begin{array}{l}\text { Opioid binding protein/cell adhesion } \\
\text { molecule-like }\end{array}$ & 600632 \\
\hline $12 p$ & VAMP1 & DKFZp686H12131, SYB1, VAMP-1 & $\begin{array}{l}\text { Vesicle-associated membrane protein } 1 \\
\text { (synaptobrevin 1) }\end{array}$ & 185880 \\
\hline $12 \mathrm{p} 12$ & GRIN2B, NMDAR2B & $\begin{array}{l}\text { MGC142178, MGC142180, NMDAR2B, } \\
\text { NR2B, hNR3 }\end{array}$ & $\begin{array}{l}\text { Glutamate receptor, ionotropic, N-methyl } \\
\text { D-aspartate } 2 B\end{array}$ & 138252 \\
\hline $12 p 13.3$ & CACNA1C & $\begin{array}{l}\text { CACH2, CACN2, CACNL1A1, CCHL1A1, } \\
\text { CaV1.2, MGC120730, TS }\end{array}$ & $\begin{array}{l}\text { Calcium channel, voltage-dependent, L } \\
\text { type, alpha } 1 \text { C subunit }\end{array}$ & 114205 \\
\hline $12 q 13$ & ERBB3 & $\begin{array}{l}\text { ErbB-3, HER3, LCCS2, MDA-BF-1, } \\
\text { MGC88033, c-erbB-3, c-erbB3, erbB3-S, } \\
\text { p180-ErbB3, p45-sErbB3, p85-sErbB3 }\end{array}$ & $\begin{array}{l}\text { v-Erb-b2 erythroblastic leukemia viral } \\
\text { oncogene homolog } 3 \text { (avian) }\end{array}$ & 190151 \\
\hline $12 q 13-q 14$ & BLOC1S1 & $\begin{array}{l}\text { BLOS1, FLJ39337, FLJ97089, GCN5L1, } \\
\text { MGC87455, MICOA, RT14 }\end{array}$ & $\begin{array}{l}\text { Biogenesis of lysosomal organelles } \\
\text { complex-1, subunit } 1\end{array}$ & 601444 \\
\hline $12 q 22-q 23$ & IGF1 & IGF1A, IGFI & $\begin{array}{l}\text { Insulin-like growth factor } 1 \text { (somatomedin } \\
\text { c) }\end{array}$ & 147440 \\
\hline $12 q 22-q 24.2$ & $P A H$ & $P H, P K U, P K U 1$ & Phenylalanine hydroxylase & 612349 \\
\hline $12 q 24$ & $D A O$ & DAAO, DAMOX, MGC35381, OXDA & D-amino-acid oxidase & $124050 / 181500$ \\
\hline $12 q 24.2-q 24.31$ & NOS1 & IHPS1, NOS, nNOS & Nitric oxide synthase 1 (neuronal) & 163731 \\
\hline $12 q 24.31$ & GPR109A & HM74a, HM74b, NIACR1, PUMAG, PUma-g & G protein-coupled receptor 109A & 609163 \\
\hline $12 q 24.31$ & GPR109B & HM74, PUMAG, Puma-g & G protein-coupled receptor 109B & 606039 \\
\hline $13 q 14-q 21$ & HTR2A & RP11-147L20.2, 5-HT2A, HTR2 & 5-Hydroxytryptamine receptor $2 \mathrm{~A}$ & 182135 \\
\hline
\end{tabular}


Table 1. Continued

\begin{tabular}{|c|c|c|c|c|}
\hline Locus & Symbol & Aliases & Title & OMIM \\
\hline $13 q 32$ & SCZD7 & & $\begin{array}{l}\text { Schizophrenia susceptibility locus/chr. } \\
\text { 13q-related }\end{array}$ & $603176 / 181500$ \\
\hline $13 q 34$ & $D A O A$ & $G 72, L G 72, S G 72$ & D-amino acid oxidase activator & $607408 / 181500$ \\
\hline $14 q 12-q 13$ & NPAS3 & $\begin{array}{l}\text { FLJ10003, FLJ11138, FLJ11605, MOP6, } \\
\text { PASD6, bHLHe12 }\end{array}$ & Neuronal PAS domain protein 3 & 609430 \\
\hline $14 q 24.3$ & NPC2 & EDDM1, HE1, MGC1333, NP-C2 & Niemann-Pick disease, type C2 & 601015 \\
\hline $14 q 31$ & GALC & & Galactosylceramidase & 606890 \\
\hline $14 q 32.32$ & AKT1 & $\begin{array}{l}\text { AKT, MGC99656, PKB, PKB-ALPHA, } \\
\quad \text { PRKBA, RAC, RAC-ALPHA }\end{array}$ & $\begin{array}{l}\text { Murine thymoma viral (v-AKT) oncogene } \\
\text { homolog-1 }\end{array}$ & 164730 \\
\hline $15 q 11-q 12$ & APBA2 & $\begin{array}{l}\text { D15S1518E, HST16821, LIN-10, } \\
\quad \text { MGC99508, MGC:14091, MINT2, X11L }\end{array}$ & $\begin{array}{l}\text { Amyloid beta (a4) precursor } \\
\text { protein-binding, family A, member } 2\end{array}$ & 602712 \\
\hline $15 q 11.2-q 12$ & GABRB3 & ECA5, MGC9051 & $\begin{array}{l}\text { Gamma-aminobutyric acid (GABA) A } \\
\text { receptor, beta } 3\end{array}$ & 137192 \\
\hline $15 q 13.3$ & MICRODEL15q13.3 & EIG7, SCZD13 & $\begin{array}{l}\text { Chromosome } 15 q 13.3 \text { microdeletion } \\
\text { syndrome }\end{array}$ & 612001 \\
\hline $15 q 13-q 15$ & $S L C 12 A 6$ & $\begin{array}{l}\text { ACCPN, DKFZp434D2135, KCC3, KCC3A, } \\
\quad \text { KCC3B }\end{array}$ & $\begin{array}{l}\text { Solute carrier family } 12 \\
\text { (potassium/chloride transporters), } \\
\text { member } 6\end{array}$ & 604878 \\
\hline $15 q 14$ & CHRNA7, FAM7A & $\begin{array}{l}\text { CHRNA7-DR1, D-10, MGC120482, } \\
\text { MGC120483, CHRNA7-2, NACHRA7 }\end{array}$ & $\begin{array}{l}\text { CHRNA7 (cholinergic receptor, nicotinic, } \\
\text { alpha 7, exons 5-10) and FAM7A (family } \\
\text { with sequence similarity 7A, exons A-E) } \\
\text { fusion }\end{array}$ & 609756 \\
\hline $15 q 15$ & SCZD10 & & $\begin{array}{l}\text { Schizophrenia disorder } 10 \text { (periodic } \\
\text { catatonia) }\end{array}$ & $605419 / 181500$ \\
\hline $15 q 21.3$ & ALDH1A2 & MGC26444, RALDH(II), RALDH2, RALDH2-T & $\begin{array}{l}\text { Aldehyde dehydrogenase } 1 \text { family, } \\
\text { member a2 }\end{array}$ & 603687 \\
\hline $15 q 24.3$ & HOMER2 & $\begin{array}{l}\text { ACPD, CPD, HOMER-2, HOMER2A, } \\
\text { HOMER2B, Vesl-2 }\end{array}$ & Homer homolog 2 (drosophila) & 604799 \\
\hline $15 q 25$ & & TRKC, gp145(trkC) & $\begin{array}{l}\text { Neurotrophic tyrosine kinase, receptor, } \\
\text { type } 3\end{array}$ & 191316 \\
\hline $15 q 26.2$ & MCTP2 & FLJ11175, FLJ33303, MGC111402 & Multiple C2 domains, transmembrane 2 & \\
\hline $16 p 13.11$ & NDE1 & FLJ20101, HOM-TES-87, NUDE, NUDE1 & $\begin{array}{l}\text { nudE Nuclear distribution gene e homolog } \\
1 \text { (A. nidulans) }\end{array}$ & 609449 \\
\hline $16 p 13.11$ & NTAN1 & DKFZp666E058 & $\mathrm{N}$-terminal asparagine amidase & \\
\hline $16 q 12.2$ & RPGRIP1L & $\begin{array}{l}\text { CORS3, DKFZp686C0668, JBTS7, } \\
\text { KIAA1005, MKS5, NPHP8 }\end{array}$ & RPGRIP1-like & 610937 \\
\hline $16 q 22.1$ & $H P$ & BP, HP2-ALPHA-2, HPA1S, MGC1111141 & Haptoglobin & 140100 \\
\hline $17 p 11.2$ & PEMT & MGC2483, PEAMT, PEMPT, PEMT2, PNMT & $\begin{array}{l}\text { Phosphatidylethanolamine } \\
\text { N-methyltransferase }\end{array}$ & 602391 \\
\hline $17 p 13.1$ & TP53 & FL192943, LFS1, TRP53, p53 & Tumor protein p53 & 191170 \\
\hline $17 p 13.1$ & NDEL 1 & DKFZp451M0318, EOPA, MITAP1, NUDEL & $\begin{array}{l}\text { nudE nuclear distribution gene e homolog } \\
\text { (A. nidulans)-like } 1\end{array}$ & 607538 \\
\hline $17 q 11.1-q 12$ & SLC6A4 & $\begin{array}{l}\text { 5-HTT, 5-HTTLPR, 5HTT, HTT, OCD1, SERT, } \\
\text { hSERT }\end{array}$ & $\begin{array}{l}\text { solute carrier family } 6 \text { (neurotransmitter } \\
\text { transporter, serotonin), member } 4\end{array}$ & 182138 \\
\hline $17 q 12$ & PPP1R1B & DARPP-32, DARPP32, FLJ20940 & $\begin{array}{l}\text { Protein phosphatase 1, regulatory } \\
\text { (inhibitor) subunit 1B }\end{array}$ & 604399 \\
\hline $17 q 21$ & CNP & CNP1 & $\begin{array}{l}2^{\prime}, 3^{\prime} \text {-cyclic nucleotide } 3^{\prime} \\
\text { phosphodiesterase }\end{array}$ & 123830 \\
\hline $17 q 21$ & GFAP & FLJ45472 & Glial fibrillary acidic protein & 137780 \\
\hline $17 q 21.1$ & ERBB2 & $\begin{array}{l}\text { CD340, HER-2, HER-2/neu, HER2, NEU, } \\
\text { NGL, TKR1 }\end{array}$ & $\begin{array}{l}\text { v-Erb-b2 erythroblastic leukemia viral } \\
\text { oncogene homolog 2, } \\
\text { neuro/glioblastoma derived oncogene } \\
\text { homolog (avian) }\end{array}$ & 164870 \\
\hline $17 q 23.3$ & ACE & $\begin{array}{l}\text { ACE1, CD143, DCP, DCP1, MGC26566, } \\
\quad M \vee C D 3\end{array}$ & $\begin{array}{l}\text { Angiotensin I converting enzyme } \\
\text { (peptidyl-dipeptidase A) } 1\end{array}$ & 106180 \\
\hline $18 p$ & SCZD8 & & Schizophrenia disorder 8 & $603206 / 181500$ \\
\hline $18 p 11.2$ & MC5R & & Melanocortin 5 receptor & 600042 \\
\hline
\end{tabular}


Table 1. Continued

\begin{tabular}{|c|c|c|c|c|}
\hline Locus & Symbol & Aliases & Title & OMIM \\
\hline 18p11.31-p11.2 & NDUFV2 & & $\begin{array}{l}\text { NADH dehydrogenase (ubiquinone) } \\
\text { flavoprotein } 2,24 \mathrm{kDa}\end{array}$ & 600532 \\
\hline $18 q 11-q 12$ & NPC1 & FLJ98532, NPC & Niemann-Pick disease, type C1 & 607623 \\
\hline $18 q 21$ & ME2 & ODS1 & $\begin{array}{l}\text { Malic enzyme } 2, N A D^{+} \text {-dependent, } \\
\text { mitochondrial }\end{array}$ & 154270 \\
\hline $18 q 21.1$ & TCF4 & $\begin{array}{l}\text { E2-2, ITF2, MGC149723, MGC149724, } \\
\text { PTHS, SEF2, SEF2-1, SEF2-1A, } \\
\text { SEF2-1B, bHLHb19 }\end{array}$ & Transcription factor 4 & 602272 \\
\hline $18 q 21.3$ & $B C L 2$ & $B C l-2$ & B-cell CLL/lymphoma 2 & 151430 \\
\hline $18 q 23$ & MBP & MGC99675 & Myelin basic protein & 159430 \\
\hline $19 p 13.3$ & $A B C A 7$ & $A B C A-S S N, A B C X, F L J 40025$ & $\begin{array}{l}\text { ATP-binding cassette, sub-family A } \\
\text { (ABC1), member } 7\end{array}$ & 605414 \\
\hline $19 q 13.1$ & MAG & GMA, S-MAG, SIGLEC-4A, SIGLEC4A & Myelin associated glycoprotein & 159460 \\
\hline $19 q 13.2$ & $A P O E$ & AD2, LDLCQ5, LPG, MGC1571 & Apolipoprotein E & 107741 \\
\hline $19 q 13.2$ & $X R C C 1$ & $R C C$ & $\begin{array}{l}\text { X-ray repair complementing defective } \\
\text { repair in chinese hamster cells } 1\end{array}$ & 194360 \\
\hline $19 q 13.3$ & PLA2GAC & $\begin{array}{l}\text { CPLA2-gamma, DKFZp586C0423, } \\
\text { FLJ42247, FLJ44164 }\end{array}$ & $\begin{array}{l}\text { Phospholipase A2, group IVC (cytosolic, } \\
\text { calcium-independent) }\end{array}$ & 603602 \\
\hline $19 q 13.32$ & BLOC1S3 & BLOS3, FLJ26641, FLJ26676, HPS8, RP & $\begin{array}{l}\text { Biogenesis of lysosomal organelles } \\
\text { complex-1, subunit } 3\end{array}$ & 609762 \\
\hline 20p12-p11.2 & SNAP25 & $\begin{array}{l}\text { FLJ23079, RIC-4, RIC4, SEC9, SNAP, } \\
\text { SNAP-25, bA416N4.2, dJ1068F16.2 }\end{array}$ & Synaptosomal-associated protein, 25kDa & 600322 \\
\hline $20 q 11.2$ & DNMT3B & ICF, M.HsallIB & $\begin{array}{l}\text { DNA (cytosine-5-)-methyltransferase } 3 \\
\text { beta }\end{array}$ & 602900 \\
\hline $20 q 11.2-q 13.1$ & MMP9 & CLG4B, GELB, MANDP2, MMP-9 & $\begin{array}{l}\text { Matrix metallopeptidase } 9 \text { (gelatinase B, } \\
\text { 92kDa gelatinase, 92kDa type IV } \\
\text { collagenase) }\end{array}$ & 120361 \\
\hline $21 q 22.11$ & OLIG2 & $\begin{array}{l}\text { BHLHB1, OLIGO2, PRKCBP2, RACK17, } \\
\text { bHLHe19 }\end{array}$ & $\begin{array}{l}\text { Oligodendrocyte lineage transcription } \\
\text { factor } 2\end{array}$ & 606386 \\
\hline $22 q 11$ & DGCR6 & & DiGeorge syndrome critical region gene 6 & 601279 \\
\hline $22 q 11.2$ & C22DDELS & C22DELq11.2 & $\begin{array}{l}\text { Chromosome 22q11.2 deletion } \\
\text { syndrome, distal }\end{array}$ & 611867 \\
\hline $22 q 11.2$ & GNB1L & $\begin{array}{l}\text { DGCRK3, FKSG1, GY2, KIAA1645, WDR14, } \\
\quad \text { WDVCF }\end{array}$ & $\begin{array}{l}\text { Guanine nucleotide binding protein (G } \\
\text { protein), beta polypeptide 1-like }\end{array}$ & 610778 \\
\hline $22 q 11.2$ & PRODH & $\begin{array}{l}\text { FLJ33744, HSPOX2, MGC148078, } \\
\text { MGC148079, PIG6, POX, PRODH1, } \\
\text { PRODH2, SCZD4, TP5316 }\end{array}$ & Proline dehydrogenase/proline oxidase & $606810 / 181500$ \\
\hline $22 q 11-q 13$ & SCZD4 & & Schizophrenia disorder 4 & $600850 / 181500$ \\
\hline $22 q 11.21$ & $A R V C F$ & FLJ35345 & $\begin{array}{l}\text { Armadillo repeat gene deletes in } \\
\text { velocardiofacial syndrome }\end{array}$ & 602269 \\
\hline $22 q 11.21$ & COMT & & Catechol-O-methyltransferase & $116790 / 181500$ \\
\hline $22 q 11.21$ & RTN4R & $N G R, N O G O R$ & Reticulon 4 receptor & 605566 \\
\hline $22 q 11.21$ & ZDHHC8 & ZDHHCL1, ZNF378 & Zinc finger, DHHC-type containing 8 & 608784 \\
\hline $22 q 11.23$ & GSTT1 & & Glutathione D-transferase theta 1 & 600436 \\
\hline $22 q 11.2-q 13.2$ & APOL4 & CTA-212A2.2, APOL-IV, APOLIV & Apolipoprotein L,4 & $607254 / 181500$ \\
\hline $22 q 11.21$ & DGCR2 & $\begin{array}{l}\text { DGS-C, DKFZp68611730, IDD, KIAA0163, } \\
\text { LAN, SEZ-12 }\end{array}$ & DiGeorge syndrome critical region gene 2 & 600594 \\
\hline $22 q 12$ & APOL2 & APOL-II, APOL3 & Apolipoprotein L,2 & $607252 / 181500$ \\
\hline $22 q 12.3$ & SYN3 & LL22NC03-28H9.1 & Synapsin III & 602705 \\
\hline $22 q 12.3$ & YWHAH & LL22NC03-44A4.1, YWHA1 & $\begin{array}{l}\text { Tyrosine 3-monooxygenase/tryptophan } \\
\text { 5-monooxygenase activation protein, } \\
\text { eta polypeptide }\end{array}$ & 113508 \\
\hline $22 q 13.1$ & APOL1 & RP1-6802.2, APO-L, APOL, APOL-I & Apolipoprotein L,1 & $603743 / 181500$ \\
\hline $22 q 13.1$ & CSF2RB & CD131, CDW131, IL3RB, IL5RB & $\begin{array}{l}\text { Colony stimulating factor } 2 \text { receptor, beta, } \\
\text { low-affinity (granulocyte-macrophage) }\end{array}$ & 138981 \\
\hline $22 q 13$ & SYNGR1 & MGC:1939 & Synaptogyrin 1 & 603925 \\
\hline
\end{tabular}


Table 1. Continued

\begin{tabular}{|c|c|c|c|c|}
\hline Locus & Symbol & Aliases & Title & OMIM \\
\hline $22 q 13.2$ & MCHR1 & GPR24, MCH1R, MGC32129, SLC1 & $\begin{array}{l}\text { Melanin-concentrating hormone receptor } \\
\quad 1\end{array}$ & 601751 \\
\hline $22 q 13.3$ & SHANK3 & $\begin{array}{l}\text { DEL22q13.3, KIAA1650, PROSAP2, PSAP2, } \\
\text { SPANK-2 }\end{array}$ & $\begin{array}{l}\text { SH3 and multiple ankyrin repeat domains } \\
3\end{array}$ & 606230 \\
\hline $22 q 13.31$ & BIK & $B I P 1, B P 4, N B K$ & $\begin{array}{l}\text { BCL2-interacting killer } \\
\text { (apoptosis-inducing) }\end{array}$ & 603392 \\
\hline $22 q 13.33$ & $B R D 1$ & BRL, BRPF1, BRPF2, DKFZp686F0325 & bromodomain containing 1 & 604589 \\
\hline $22 q 13.33$ & $M L C 1$ & RP3-355C18.4, KIAA0027, LVM, MLC, VL & MLC1 gene & 605908 \\
\hline $22 q 13.33$ & ZBED4 & & Zinc finger, BED-type containing 4 & 612552 \\
\hline Xp11.23 & MAOB & RP1-201D17_B.1, MGC26382 & Monoamine oxidase B & 309860 \\
\hline$X q 13.1$ & NLGN3 & HNL3, KIAA1480 & Neuroligin 3 & 300336 \\
\hline Xp22.1 & SAT1 & DC21, KFSD, KFSDX, SAT, SSAT, SSAT-1 & $\begin{array}{l}\text { Spermidine/spermine } \\
\text { N1-acetyltransferase } 1\end{array}$ & 313020 \\
\hline Xp22.32-p22.31 & NLGN4 & $\begin{array}{l}\text { ASPGX2, AUTSX2, HLNX, HNLX, } \\
\text { KIAA1260, MGC22376, NLGN, NLGN4 }\end{array}$ & Neuroligin 4, X-linked & 300427 \\
\hline $\mathrm{Xq} 24$ & HTR2C & RP11-81003.1, 5-HT2C, 5-HTR2C, HTR1C & $\begin{array}{l}\text { 5-Hydroxytryptamine (serotonin) receptor } \\
2 \mathrm{C}\end{array}$ & 312861 \\
\hline $\mathrm{Xq} 28$ & MECP2 & $\begin{array}{l}\text { AUTSX3, DKFZP686A24160, MRX16, } \\
\text { MRX79, MRXS13, MRXSL, PPMX, RS, } \\
\text { RTS, RTT }\end{array}$ & $\begin{array}{l}\text { Methyl CPG binding protein } 2 \text { (Rett } \\
\text { syndrome) }\end{array}$ & 300005 \\
\hline Xp22.3 or Yp11.3 & IL3RA & $\begin{array}{l}R P 11-261 P 4.2, C D 123, \text { IL3R, IL3RAY, } \\
\quad \text { IL3RX, IL3RY, MGC34174, hIL-3Ra }\end{array}$ & Interleukin 3 receptor, alpha (low affinity) & 308385,430000 \\
\hline \multicolumn{5}{|l|}{ GWA 10q2613 } \\
\hline \multicolumn{5}{|l|}{ GWA 11p141 } \\
\hline GWA 16p1312 & & & & \\
\hline
\end{tabular}

predominantly controlled by the Liver X receptor (LXR) transcription factor, have been detected. Stimulation of cellular lipid biosynthesis by amphiphilic psychotropic drugs is followed by a transcriptional activation of cholesterol transport and efflux pathways. Such effects may be relevant for both therapeutic effects and metabolic adverse effects of psychotropic drugs [28].

\section{Apoptotic Engulfment Pathway}

Apoptosis has been speculated to be implicated in SCZ. The apoptotic engulfment pathway involving the MEGF10, GULP1, ABCA1, and $A B C A 7$ genes have been investigated in SCZ. Nominally significant associations were found in GULP1 (rs2004888), ABCA1 (rs3858075), and $A B C A 7$ genes. A significant 2-marker (rs2242436 * rs3858075) interaction between the $A B C A 1$ and $A B C A 7$ genes and a 3-marker interaction (rs246896 * rs4522565* rs3858075) among the MEGF10, GULP1, and ABCA1 genes were found in different samples [29].

\section{Brain-Derived Neurotrophic Factor (BDNF)}

A variety of evidence suggests $B D N F$ as a candidate gene for SCZ, and several genetic studies have shown a significant association between the disease and certain SNPs within BDNF (specifically, Val66Met and $\mathrm{C} 270 \mathrm{~T}$ ). The functional microsatellite marker $B D N F-L C P R$ (BDNF-linked complex polymorphic region), which affects the expression level of BDNF, is associated with BD. A meta-analysis of the two most extensively studied polymorphisms (Val66Met and C270T) revealed no association in single-marker or multimarker analysis and no association of Val66Met polymorphism with SCZ, whereas C270T showed a trend for association in a fixed model, but not in a random model. These findings suggest that if BDNF is indeed associated with SCZ, the Al allele in BDNF$L C P R$ would be the most promising candidate [30]. In a Taiwanese population no association between the BDNF Val66Met polymorphism and SCZ was found; however, this polymorphism may reduce psychopathology, in particular negative symptoms [31]. Patients with schizoaffective disorder and other affective disorders are significantly more likely to carry two copies of the most common BDNF haplotype compared with healthy volunteers. When compared with SCZ patients, individuals with schizoaffective disorder are significantly more likely to carry two copies of the common haplotype [32]. Defective BDNF has been proposed as a candidate pathogenic mechanism in SCZ and dementia. BDNF transcription is regulated during the protracted period of human frontal cortex development. Expression of the four most abundant alternative $5^{\prime}$ exons of the BDNF gene (exons I, II, IV, and VI) has been studied in RNA extracted from the prefrontal cortex. Expression of transcripts I-IX and VI-IX was highest during infancy, whereas that of transcript II-IX was lowest just after birth, slowly increasing to reach a peak in toddlers. Transcript IV-IX was significantly upregulated within the first year of life, and was maintained at this level until school age. Quantification of BDNF 
Table 2. Top polymorphisms in top 30 genes at SZ gene $[15,159]$

\begin{tabular}{|c|c|c|c|}
\hline SZGene & Gene & SNPs & Allele (minor/major) \\
\hline 1 & DISC1 & rs3737597 & $A_{-}^{*} / G$ \\
\hline 2 & SLC18A1 & rs2270641 & $\mathrm{C}_{-}^{*} / \mathrm{A}$ \\
\hline 3 & GABRB2 & None & \\
\hline \multirow[t]{4}{*}{4} & DRD2 & rs1079597 (Taql-B) & $\mathrm{A} / \mathrm{G}_{-}^{*}$ \\
\hline & & rs6277 & $\mathrm{C}_{-}^{*} / \mathrm{T}$ \\
\hline & & rs1801028 & $\mathrm{G}_{-}^{*} / \mathrm{C}$ \\
\hline & & rs6275 & $\mathrm{T}_{-}^{*} / \mathrm{C}$ \\
\hline 5 & GWA $10 q 2613$ & rs17101921 & $A_{-}^{*} / G$ \\
\hline 6 & AKT1 & rs3803300 & $A_{-}^{*} / G$ \\
\hline \multirow[t]{2}{*}{7} & GRIN2B & rs1019385 & $T / G_{-}^{*}$ \\
\hline & & rs7301328 & $\mathrm{G}_{-}^{*} / \mathrm{C}$ \\
\hline 8 & DGCR2 & rs2073776 & $A_{-}^{*} / G$ \\
\hline 9 & PLXNA2 & rs1327175 & $\mathrm{G} / \mathrm{C}_{-}^{*}$ \\
\hline 10 & RPGRIP1L & rs9922369 & $A_{-}^{*} / G$ \\
\hline 11 & TPH1 & rs1800532 & $\mathrm{A}_{-}^{*} / \mathrm{C}$ \\
\hline \multirow[t]{2}{*}{12} & DRD4 & 120-bp TR & $S / L_{-}^{*}$ \\
\hline & & rs1800955 & $\mathrm{C}_{-}^{*} / \mathrm{T}$ \\
\hline \multirow[t]{3}{*}{13} & $D A O A$ & rs3916971 & $\mathrm{T} / \mathrm{C}_{-}^{*}$ \\
\hline & & rs778294 & $\mathrm{T} / \mathrm{C}_{-}^{*}$ \\
\hline & & rs2391191 (M15) & $A_{-}^{*} / G$ \\
\hline 14 & GWA 11p141 & rs1602565 & $\mathrm{C}_{-}^{*} / \mathrm{T}$ \\
\hline 15 & $D R D 1$ & none & \\
\hline 16 & HTR2A & rs6311 & $\mathrm{A} /{ }_{-}^{*} \mathrm{G}$ \\
\hline 17 & RELN & rs7341475 & $\mathrm{A} / \mathrm{G}_{-}^{*}$ \\
\hline 18 & $A P O E$ & & $\mathrm{e} 2 / 3 / 4_{-}^{*}$ \\
\hline \multirow[t]{3}{*}{19} & $N R G 1$ & rs2439272 & $\mathrm{A} / \mathrm{G}_{-}^{*}$ \\
\hline & & rs35753505 & $\mathrm{C}_{-}^{*} / \mathrm{T}$ \\
\hline & & rs473376 & $\mathrm{G}_{-}^{*} / \mathrm{A}$ \\
\hline 20 & $\operatorname{IL1B}$ & rs1143634 & $\mathrm{T} / \mathrm{C}_{-}^{*}$ \\
\hline 21 & MTHFR & rs1801133 & $\mathrm{T}_{-}^{*} / \overline{\mathrm{C}}$ \\
\hline \multirow[t]{2}{*}{22} & СOMT & rs4680 & $\mathrm{A} / \mathrm{G}_{-}^{*}$ \\
\hline & & rs737865 & $\mathrm{C} / \mathrm{T}_{-}^{*}$ \\
\hline 23 & $H P$ & $\mathrm{Hp} 1 / 2$ & $1 / 2_{-}^{*}$ \\
\hline \multirow[t]{4}{*}{24} & $D A O$ & rs2111902 & $\mathrm{G}_{-}^{*} / \mathrm{T}$ \\
\hline & & rs3741775 & $\mathrm{C} / \mathrm{G}_{-}^{*}$ \\
\hline & & rs3918346 & $A_{-}^{*} / G$ \\
\hline & & rs4623951 & $\overline{\mathrm{C} / \mathrm{T}_{-}^{*}}$ \\
\hline 25 & TP53 & rs1042522 & $C_{-}^{*} / \bar{G}$ \\
\hline 26 & ZNF804A & rs1344706 & $\mathrm{G} / \mathrm{T}_{-}^{*}$ \\
\hline 27 & GWA 16p1312 & rs71992086 & $\mathrm{T}_{-}^{*} / \mathrm{A}$ \\
\hline \multirow[t]{4}{*}{28} & DTNBP1 & rs1011313 & $\mathrm{T}_{-}^{*} / \mathrm{C}$ \\
\hline & & rs1018381 & $\mathrm{T} /{ }_{-}^{*} \mathrm{C}$ \\
\hline & & rs2619538(SNPA) & $\mathrm{T}_{-}^{*} / \mathrm{A}$ \\
\hline & & rs3213207(P1635) & $\mathrm{G} / \mathrm{A}_{-}^{*}$ \\
\hline 29 & $O P C M L$ & rs3016384 & $\mathrm{T} / \mathrm{C}_{-}^{*}$ \\
\hline 30 & RGS4 & rs2661319 (SNP16) & $\mathrm{A} / \mathrm{G}_{-}^{*}$ \\
\hline
\end{tabular}

protein revealed that levels followed a similar developmental pattern as transcript IV-IX. In situ hybridization of mRNA in cortical sections showed the highest expression in layers V and VI for all four BDNF transcripts, whereas moderate expression was observed in layers II and III. These findings reported by Wong et al. [33] show that dynamic regulation of BDNF expression occurs through differential use of alternative promoters during the development of the human prefrontal cortex, particularly in the younger age groups, when the prefrontal cortex is more plastic. Alterations in BDNF processing during brain maturation cannot be neglected as a potential mechanism for prefrontal cortex dysfunction in SCZ. The levels of (pro)BDNF and receptor proteins, TrkB and p75, are altered in hippocampus in SCZ and mood disorder and polymorphisms in each gene influence protein expression [34]. Neurodegenerative processes may be involved in the pathogenesis of tardive dyskinesia (TD), and a growing body of evidence suggests that BDNF plays a role in both the antipsychotic effects and the pathogenesis of TD. BDNF and glycogen synthase kinase (GSK)3beta are important in neuronal survival, and thus abnormal regulation of BDNF and GSK-3beta may contribute to TD pathophysiology. Park et al. [35] studied the relationship between two polymorphisms, Val66Met in the BDNF coding region and 50T/C in the GSK-3beta promoter, and susceptibility to TD among a matched sample of patients having SCZ with TD, patients with SCZ without TD, and normal control subjects. Polymerase chain reaction (PCR) analysis revealed no significant difference in the occurrence of the polymorphisms among the TD, non-TD, and control subjects, but a significant interaction was observed among the groups possessing $B D N F$ Val allele in compound genotypes. The schizophrenic subjects with the C/C GSK-3beta genotype, who carry the Val allele of the $B D N F$ gene, are expected to have a decreased risk of developing neuroleptic-induced TD [35].

\section{Biogenesis of Lysosome-Related Organelles Complex 1 (BLOC-1)}

BLOC-1 is a protein complex formed by the products of eight distinct genes. Loss-of-function mutations in two of these genes, DTNBP1 and BLOC1S3, cause Hermansky-Pudlak syndrome, a human disorder characterized by defective biogenesis of lysosomerelated organelles. Haplotype variants within the same two genes have been postulated to increase the risk of developing SCZ [36].

\section{Calcium Channel, Voltage-Dependent, L Type, Alpha 1C Subunit (CACNA1C)}

Strong evidence of association at the polymorphism rs1006737 (within CACNA1C, the gene encoding the alpha-1C subunit of the L-type voltage-gated calcium channel) with the risk of $\mathrm{BD}$ has recently been reported in a meta-analysis of three genome-wide association studies of BD. The risk allele also conferred increased risk for SCZ and recurrent major depression with similar effect sizes to those previously observed in BD $[37,38]$.

\section{Cannabinoid Receptors}

Two endocannabinoid receptors, $\mathrm{CB} 1$ and $\mathrm{CB} 2$, are found in the brain. The R63 allele of rs2501432 (R63Q), the C allele of rs 12744386 and the haplotype of the R63-C allele of CB2 were significantly increased among patients with SCZ [39]. 


\section{Cholecystokinin A Receptor (CCK-AR) Gene}

CCK-AR has been implicated in the pathophysiology of SCZ through its mediation of dopamine-release in the CNS. Association between the CCK-AR gene and SCZ has been observed, especially between the $779 \mathrm{~T} / \mathrm{C}$ polymorphism and auditory hallucinations or positive symptoms of SCZ [40].

\section{Alpha-7 Nicotinic Acetylcholine Receptor (CHRNA7)}

Multiple genetic linkage studies support the hypothesis that the 15q13-14 chromosomal region contributes to the etiology of SCZ. Among the putative candidate genes in this area are CHRNA7 and its partial duplication, CHRFAM7A. A large chromosomal segment including the CHRFAM7A gene locus, but not the CHRNA7 locus, is deleted in some individuals. The CHRFAM7A gene contains a polymorphism consisting of a 2 base pair ( $2 \mathrm{bp}$ ) deletion at position $497-498$ bp of exon 6 . The 2 bp polymorphism was associated with SCZ in African-Americans, and in Caucasians [41]. The rs3087454 SNP, located at position $-1831 \mathrm{bp}$ in the upstream regulatory region of CHRNA7, was significantly associated with SCZ in African-American and Caucasian-Non-Hispanic case-control samples [42].

\section{CNTNAP2, NRXN1, and the Neurexin Superfamily}

Heterozygous CNV and SNPs of CNTNAP2 and NRXN1, two distantly related members of the neurexin superfamily, have been repeatedly associated with a wide spectrum of neuropsychiatric disorders, such as developmental language disorders, autism spectrum disorders, epilepsy, Pitt-Hopkins syndrome, and SCZ [43].

\section{Catechol-O-Methyltransferase (COMT)}

The COMT gene, which is located in the $22 \mathrm{q} 11$ microdeletion, has been considered as a candidate gene for SCZ due to its ability to degrade catecholamines, including dopamine. Human COMT contains three common polymorphisms (A22S, A52T, and V108M), two of which (A22S and V108M) render the protein susceptible to deactivation by temperature or oxidation. The A52T mutation had no significant effect on COMT structure. The A22S and V108M polymorphisms evolved independently in Northern European and Asian populations. While the decreased activities of both A22S and V108M COMT are associated with an increased risk for SCZ, the V108M-induced destabilization is also linked with improved cognitive function. Polymorphisms within this hotspot may have evolved to regulate COMT activity, and heterozygosity for either mutation may be advantageous [44]. Some studies revealed potential epistatic effects of two intronic SNPs located in the COMT and aldehyde dehydrogenase 3Bl (ALDH3B1) genes, which conferred genetic risk to paranoid SCZ. Among the individuals carrying the rs3751082 A allele in the $A L D H 3 B 1$ gene, the rs4633 $\mathrm{T}$ allele in the COMT gene was associated with susceptibility to paranoid SCZ, development of hallucination, delay of P300 latency, and increased expression of the COMT gene; however, the rs4633
T allele did not show any association in the rs3751082 G/G genotype carriers [45].

\section{D-amino Acid Oxidase Activator (DAOA)}

The DAOA gene locus on chromosome 13q32-q34 has been implicated in the etiology of SCZ. Three SNPs (rs778294, rs779293, and rs3918342) have been identified in this region, and two of them (rs778293 and rs3918342) have shown significant transmission disequilibrium and a highly significant under-transmission between haplotype CAT and SCZ [46]. G72 is one of the most widely tested genes for association with SCZ. As G72 activates the D-amino acid oxidase (DAO), G72 is termed DAOA. Ohi et al. [47] found nominal evidence for association of alleles, M22/rs778293, M23/rs3918342, and M24/rs1421292, and the genotype of M22/rs778293 with SCZ, although there was no association of allele or genotype in the other 5 SNPs. They also found nominal haplotypic association, including M15/rs2391191 and M19/rs778294 with SCZ [47]. Association of the G72/G30 locus with SCZ and BD has been reported in several studies. The G72/G30 locus spans a broad region of chromosome 13q. One meta-analysis of published association studies shows highly significant evidence of association between nucleotide variations in the G72/G30 region and SCZ, along with compelling evidence of association with BD [48]. This locus has been associated with panic disorder, SCZ, and BD, specially the 3 SNPs rs2391191, rs3918341, and rs 1935062, with controversial results [49].

\section{Disrupted-In-Schizophrenia (DISC)-1 (DISC1)}

The DISC1 locus is located at the breakpoint of a balanced $t(1 ; 11)$ (q42.1;q14.3) chromosomal translocation in a large and unique Scottish family. This translocation segregates in a highly statistically significant manner with a broad diagnosis of psychiatric illness, including SCZ, BD and major depression, as well as with a narrow diagnosis of SCZ alone. Two novel genes were identified at this locus and due to the high prevalence of SCZ in this family, they were named DISC-1 (DISC1) and DISC-2 (DISC2). DISC1 encodes a novel multifunctional scaffold protein, whereas DISC2 is a putative noncoding RNA gene antisense to DISC1. A number of independent genetic linkage and association studies in diverse populations support the original linkage findings in the Scottish family and genetic evidence now implicates the DISC locus in susceptibility to SCZ, schizoaffective disorder, BD and major depression, as well as various cognitive traits [50].

DISC 1 interacts directly with phosphodiesterase 4B (PDE4B), an independently identified risk factor for SCZ. DISC1-PDE4B complexes are therefore likely to be involved in molecular mechanisms underlying psychiatric illness. PDE4B hydrolyzes cAMP and DISC1 may regulate CAMP signaling through modulating PDE4B activity. There is evidence that expression of both genes is altered in some psychiatric patients. DISC1 missense mutations that give rise to phenotypes related to $S C Z$ and depression in mice are located within binding sites for $P D E 4 B$. These mutations reduce the association between DISC1 and PDE4B, and one results in reduced brain PDE4B activity. Altered DISC1-PDE4B interaction may thus underlie the symptoms of some cases of SCZ and 
depression [51]. DISCl protein binding partners include the Nuclear Distribution Factor E Homologs (NDEl and NDEL1), LIS1, and phosphodiesterases 4B and 4D (PDE4B and PDE4D) [52]. A DISC1 haplotype, HEP3, and an NDE1 spanning tag haplotype are associated with SCZ in Finnish families. Tomppo et al. [53] identified 3 SNPs to be associated with SCZ in PDE4D (rs1120303), PDE4B (rs7412571), and NDEL1 (rs17806986). Greater significance was observed with allelic haplotypes of $P D E 4 D, P D E 4 B$, and NDEL1 that increased or decreased SCZ susceptibility, highlighting the potential importance of DISC1-related molecular pathways in the etiology of SCZ and other major mental illnesses [53]. Kähler et al. [54] have genotyped and analyzed 40 and 72 tagSNPs in SCZ and BP multicenter samples, respectively, from the Scandinavian Collaboration on Psychiatric Etiology (SCOPE), involving 837 SCZ cases and 1473 controls plus 594 BP cases and 1421 partly overlapping controls. Six and 16 tagSNPs were nominally associated with SCZ and BP, respectively, in the combined samples or in gender-specific subgroups. None of these findings remained significant after correction for multiple testing. However, a number of tagSNPs found to be nominally associated with SCZ and BP were located in a high linkage disequilibrium (LD) region spanning the splice site of $P D E 4 B 3$, an isoform with altered brain expression in BP patients.

\section{DNA Methyltransferase 3B}

Aberrant DNA methylation may be involved in the development of SCZ. DNA methyltransferase 3B (DNMT3B) is the key methyltransferase in DNA methylation regulations. Case-control and family-based studies were performed through genotyping two tag SNPs (rs2424908 and rs6119954) covering the whole DNMT3B gene. The frequency of G allele of rs6119954 was significantly higher in SCZ. Genotype distribution of rs6119954 was significantly different between patients and controls. A haplotypewise analysis revealed a higher frequency of the T-G (rs2424908rs6119954) haplotype in SCZ [55]. In SCZ a functional downregulation of the prefrontal cortex GABAergic neuronal system is mediated by a promoter hypermethylation, presumably catalyzed by an increase in DNA-methyltransferase-1 (DNMT1) expression. This promoter hypermethylation may be mediated not only by DNMT-1 but also by an entire family of de novo DNA-methyltransferases, such as DNA-methyltransferase-3a (DNMT-3a) and -3b (DNMT-3b) [56].

\section{Dopamine-Related Genes}

\section{DARPP-32 (PPP1R1B)}

Recent findings have highlighted the importance of DARPP-32 (dopamine- and cAMP-regulated phosphoprotein, $32 \mathrm{kDa}$ ), a key regulatory molecule in the dopaminergic signaling pathway for dopamine-related phenotypes like antisocial-behavior, drug addiction, and SCZ [57].

\section{Dopamine Beta-Hydroxylase}

The SNP rsl108580 A/G in DBH has been associated with SCZ [58].

\section{Dopamine Transporter (DAT) 3' UTR VNTR}

Dopamine has a crucial role in the modulation of neurocognitive function, and synaptic dopamine activity is normally regulated by DAT and COMT. Altered dopamine function is a key pathophysiological feature of SCZ [59].

\section{Dopamine Receptor D2 (DRD2)}

Associations of two SNPs for DRD2 (rsl1608185, rs6275) were found [60].

\section{Dopamine D4 Receptor (DRD4)}

Associations have been reported between the variable number of tandem repeat (VNTR) polymorphisms in the exon 3 of DRD4 and multiple psychiatric illnesses/traits. The size of allele " $7 \mathrm{R}$ " is less frequent $(0.5 \%)$ in the Japanese than in Caucasian populations $(20 \%)$. The most common $4 \mathrm{R}$ variant is considered to be the ancestral haplotype [61]. A haplotype containing rs3732782, rs 905568 , and rs7620754 in the $5^{\prime}$ region of DRD3 was associated with TD [62].

\section{Tyrosine Hydroxylase (TH)}

TH (EC 1.14.16.2) is involved in the conversion of phenylalanine to dopamine. As the rate-limiting enzyme in the synthesis of catecholamines, TH has a key role in the physiology of adrenergic neurons. The $T H$ variant $\mathrm{rs} 6356 \mathrm{~A} / \mathrm{G}$ has been associated with SCZ [58].

\section{Dystrobrevin Binding Protein 1 (DTNBP1) and Dysbindin}

$D T N B P 1$, a gene encoding dysbindin protein, is a susceptibility gene for SCZ identified by family-based association analysis. Up to 14 SNPs spanning the DTNBP1 locus may show association with SCZ in different studies [63]; however, a high-resolution melting analysis (HRMA) to screen the 11 DTNBP1 exons with their corresponding DNA variants in a sample from United Kingdom revealed no significant associations with SCZ [64]. DTNBP1 and MUTED, encode proteins that belong to the endosome-localized BLOC-1 complex. BLOC-1 plays a key role in endosomal trafficking and as such has been found to regulate cell-surface abundance of the D2 dopamine receptor, the biogenesis and fusion of synaptic vesicles, and neurite outgrowth [65]. BLOC-1 interacts with the adaptor protein (AP)-3 complex, which is essential for vesicle or protein sorting. A 3-marker C-A-T dysbindin haplotype is associated with increased risk for $\mathrm{SCZ}$, decreased mRNA expression, reduced gray matter volume in both the right dorsolateral prefrontal and left occipital cortex, poorer cognitive performance, and early sensory processing deficits [66]. Four SNPs (rs3213207, rs1011313, rs760761, and rs2619522) have been genotyped in a large Korean SCZ sample. Haplotype analyses revealed a significant association with SCZ with the haplotypes A-C-C-C and A-C-T-A having an eminent protective effect toward SCZ. The major 
contribution to the difference in the haplotype distribution between patients and controls was the rs760761 (C/T) and rs2619522 (A/C) haplotypes [67]. Seven DTNBP1 SNPs (rs2743852 (SNP C), rs760761 (P1320), rs1011313 (P1325), rs3213207 (P1635), rs2619539 (P1655), rs16876571, and rs 17470454) were investigated in BP, and significant differences in genotypic and allelic frequencies of rs3213207 and rs760761 of DTNBP1 were found between bipolar patients and controls [68].

\section{Estrogen Signaling}

Estrogen signaling may be altered in the brains of people with SCZ. DNA sequence variation in the estrogen receptor $(E R)$ alpha gene, lower ERalpha mRNA levels, and/or blunted ERalpha signaling is associated with SCZ. Reductions in the transcriptionally active form of ErbB4 comprising the intracytoplasmic domain (ErbB4ICD) have been found in SCZ. Convergence between ERalpha and ErbB4-ICD in the transcriptional control of ERalpha-target gene expression may represent a convergent pathway that may be disrupted in SCZ [69]. Li et al. [70] investigated the ERBB3 gene given the putative functional nature of the gene and population heterogeneity between Asian and Caucasian. Scottish case and control samples were sequenced with 4 SNPs (rs705708 at intron 15, rs2271189, rs773123, rs2271188 at exon 27), and association of rs773123, which is a nonsynonymous Ser/Cys polymorphism located 7 bases downstream of rs2271189, with SCZ was detected in the Caucasian population [70]. The estrogen protection hypothesis proposes that estrogen has a protective effect against onset of SCZ. Epidemiological studies have shown that young women are less likely to develop SCZ than men of the same age, and women are more likely to develop late-onset SCZ after menopause. Clinical studies have shown higher psychotic symptoms in perimenopausal women, and women at the low estrogen phase of the menstrual cycle [71].

\section{FADS2: Delta-6 Desaturase}

Emerging evidence suggests that SCZ might be associated with peripheral and central polyunsaturated fatty acid (PUFA) deficits. Abnormalities in fatty acid composition have been reported in peripheral tissues from drug-naïve first-episode schizophrenic patients, including deficits in omega-3 and omega-6 PUFAs, which are partially normalized following chronic antipsychotic treatment. Postmortem cortical tissue from patients with SCZ also exhibit deficits in cortical docosahexaenoic acid (DHA, 22:6n-3) and arachidonic acid (AA; 20:4n-6) relative to normal controls, and these deficits tend to be greater in drug-free SCZ patients [72]. Delta-5 desaturase (FADS1), Delta-6 desaturase (FADS2), elongase (HELO1 [ELOVL5]), peroxisomal (PEX19), and Delta-9 desaturase (stearoyl-CoA desaturase, $S C D$ ) mRNA expression has been studied in the postmortem prefrontal cortex of patients with SCZ. FADS2 mRNA expression was significantly greater in SCZ patients relative to controls $(+36 \%)$, and there was a positive trend found for FADS1 (+26\%). Drug-free SCZ patients $(+37 \%)$, and SCZ patients treated with typical $(+40 \%)$ or atypical $(+31 \%)$ antipsychotics, exhibited greater FADS2 mRNA expression relative to controls. Consistent with increased Delta6 desaturase activity, SCZ patients exhibited a greater PUFA (product:precursor) 20:3/18:2 ratio $(+20 \%)$ and a positive trend was found for 20:4/18:2 (+13\%) [73].

\section{Fyn}

Fyn, a Src-family kinase, is highly expressed in brain tissue and blood cells. Fyn participates in brain development, synaptic transmission through the phosphorylation of NMDA receptor subunits, and the regulation of emotional behavior. Fyn is required for the signal transduction in striatal neurons that is initiated by haloperidol. Fyn abnormalities are present in patients with SCZ. At the mRNA level, the splicing patterns of Fyn were altered in the patients and their relatives; specifically, the ratio of FynDelta7, in which exon 7 is absent, was elevated [74]. Fyn plays a key role in the interaction between BDNF and glutamatergic receptor NMDA. An association was found between $F Y N$ polymorphisms and cognitive test performance in schizophrenic patients. rs706895 ($93 \mathrm{~A} / \mathrm{G}$ in the $5^{\prime}$-flanking region), rs6916861 (Ex12+894T/G in the $3^{\prime}$-UTR), and rs3730353 (IVS10 + 37T/C in intron 10) were investigated in $\mathrm{BD}$, and a significant association was found between rs6916861 T/G and rs3730353 T/C and BD [75].

\section{GABAergic Gene Expression}

Prefrontal deficits in gamma-aminobutyric acid (GABA) and GABAergic gene expression, including neuropeptide Y $(N P Y)$, somatostatin $(S S T)$, and parvalbumin $(P V)$ messenger RNAs (mRNAs), have been reported for multiple SCZ cohorts. Preclinical models suggest that a subset of these GABAergic markers (NPY/SST) is regulated by BDNF, which in turn is under the inhibitory influence of small noncoding RNAs. Subjects with SCZ show deficits in NPY and PV mRNAs [76].

\section{Glutamatergic Neurotransmission GCLM}

Glutathione and its rate-limiting synthesizing enzyme, the glutamate-cysteine ligase (GCL), are involved in the pathogenesis of SCZ. Genetic association was reported between 2 SNPs lying in noncoding regions of the glutamate cysteine ligase modifier (GCLM) gene, which specifies for the modifier subunit of GCL and SCZ [77]. Other genes involved in glutamate neurotransmission include glutamate transporter genes (EAAT1, EAAT2, EAAT3, EAAT4, vGluT1) [78], glutamic acid decarboxylase 2 (GAD2), and the glutamine synthetase $(G L U L)$ genes, glutamate receptor genes (GRIA4, GRIN2D, GRIK3, GRIK4, GRIK5, GRM3, GRID1), glutaminase, glutamate carboxypeptidase II (GCPII), group III metabotropic glutamate receptor genes (GRM4 and GRM7), NM$D A R$, and glycine- and serine-related genes (PHGDH, SHMTI, SRR, and $D A O)$.

\section{Golli-MBP}

Multiple studies have reported oligodendrocyte and myelin abnormalities, as well as dysregulation of their related genes, in brains 
of SCZ patients. One of these genes is the myelin-basic-protein $(M B P)$ gene, which encodes two families of proteins: classic-MBPs and golli-MBPs. While the classic-MBPs are predominantly located in the myelin sheaths of the nervous system, the golli proteins are more widely expressed and are found in both the immune and the nervous systems. Association between 6 (out of 26 genotyped) SNPs has been found in Jewish Ashkenazi cohorts. Of these, three (rs12458282, rs2008323, rs721286) are from one LD block, which contains a CTCF binding region. Haplotype analysis revealed significant "risk"/"protective" haplotypes for SCZ, suggesting that golli-MBP is a possible susceptibility gene for SCZ [79].

\section{Growth Factor Signaling Pathways}

Evidence has accumulated that the activity of the signaling cascades of Neuregulin-1, Wnt, TGF-beta, BDNF-p75, and DISC1 is different between control subjects and patients with SCZ. These pathways are involved in embryonic and adult neurogenesis and neuronal maturation. Clinical data indicate that in SCZ the Wnt pathway is most likely hypoactive, whereas the Nrgl-ErbB4, the TGF-beta- and the BDNF-p75-pathways are hyperactive. Haploinsuffiency of the DISC1 gene is currently the best established SCZ risk factor.

\section{Interleukins}

SCZ has been associated with abnormalities in cytokines and cytokine receptors potentially link to a defective immunological function in psychotic disorders. Some reports have shown that $I L$ $1 B, I L-3$ gene, colony stimulating factor 2 receptor alpha (CSF2RA), and IL-3 receptor alpha (IL3RA) are associated with SCZ [80].

\section{KCNH2 (Potassium Voltage-Gated Channel, Subfamily h [Eag-Related], Member 2)}

Organized neuronal firing is crucial for cortical processing and this is disrupted in SCZ. In SCZ hippocampus, $\mathrm{KCNH} 2-3.1$ expression is 2.5-fold greater than $\mathrm{KCNH} 2-1 \mathrm{~A}$ expression. A meta-analysis of 5 clinical data sets shows association of SNPs in $K C N H 2$ with SCZ [81].

\section{Kynurenine Pathway}

Some studies of mRNA expression, protein expression, and pathway metabolite levels have implicated dysregulation of the kynurenine pathway in the etiology of SCZ and BD. A SNP in each of 6 genes, TDO2, HM74, HM74A, MCHR1, MCHR2, and MC5R, was tested for association with SCZ. An A allele in $H M 74$ was significantly associated with SCZ and with SCZ plus BD combined [82].

\section{MCTP2}

The MCTP2 gene is involved in intercellular signal transduction and synapse function. Djurovic et al. [83] genotyped 37 tagging SNPs across the MCTP2 gene to study a possible association with SCZ in three independent Scandinavian samples, and found a pos- sible involvement of MCTP2 as a potential novel susceptibility gene for SCZ [83].

\section{Major Histocompatibility Complex (MHC)}

The International Schizophrenia Consortium [84] and the European SGENE-plus [85] found significant association with several markers spanning the MHC region on chromosome 6p21.3-22.1. In the $\mathrm{MCH}$ region, the 5 genome-wide significant markers (MCH/HIST1H2BJ: rs6913660-C; MHC/PRSS16: rs13219354T; MHC/PRSS16: rs6932590-T; MHC/PGBD1: rs13211507-T; MHC/NOTCH4: rs3131296-G) have risk alleles with average control frequencies between 78 and $92 \%$. The 5 chromosome $6 \mathrm{p}$ markers, spanning about $5 \mathrm{Mb}$, cover $1.4 \mathrm{cM}$ and exhibit substantial linkage disequilibrium. Rs3131296 shows correlation with classical HLA alleles (HLA-A*0101, HLA-B*0801, HLA-C*0701, HLA$D R B * 0301, H L A-D Q A * 0501, H L A-D Q B * 0201)$ [84,85]. This finding might give support to the infective-neuroimmune hypothesis of SCZ.

\section{Methylenetetrahydrofolate Reductase (MTHFR)}

The frequency of homozygosity for the 677T allele of the MTHFR gene was found higher in Chinese patients with SCZ than in controls. Both elevated plasma homocysteine levels and variation in the MTHFR $677 \mathrm{C}->\mathrm{T}$ gene is related to increased rates of SCZ and is risk factor for psychosis [86].

\section{Neuregulin (NRG1, NRG3)}

Chromosome 8p22-p1l has been identified as a locus for SCZ in several genome-wide scans and confirmed by meta-analysis of published linkage data. Systematic fine mapping using extended Icelandic pedigrees identified an associated haplotype in the gene neuregulin 1 (NRG1), also known as heuregulin, glial growth factor, NDF43, and ARIA. A $290 \mathrm{~kb}$ core at risk haplotype at the $5^{\prime}$ end of the gene (HAP[ICE]), defined by 5 SNPs and 2 microsatellite polymorphisms was found to be associated with SCZ in the Icelandic and Scottish populations. Significant association was found with 5 SNPs located in the second intron of NRG1 [87]. Li et al. [88] analyzed data from the SNP markers SNP8NRG241930, SNP8NRG243177, SNP8NRG221132, and SNP8NRG221533, and the microsatellite markers 478B14-848, 420M9-1395, and found strong positive association for all 6 polymorphisms. Gong et al. [89] performed a meta-analysis of 26 published case-control and family-based association studies up to September 2008 covering 8049 cases, 8869 controls, and 1515 families. Across these studies, the conclusions are as follows: (1) only SNP8NRG221132, 420M9-1395(0) and 478B14-848(0) showed significant association in the relatively small sample size; (2) the association analysis of case-control studies was statistically consistent with that of family studies; and (3) the matrix of coancestry coefficient suggested obvious population stratification. The study reveals that 1 SNP of the NRG1 gene does not contribute significantly to SCZ and that population stratification is evident [81]. Quantitative real-time PCR was used to check the genotypes 
of 4 SNPs-rs221533(C/T), rs7820838(C/T), 433E1006(A/G), and rs3924999 $(\mathrm{C} / \mathrm{T})$, located at the $5^{\prime}$ terminus of the NRG1 gene, in 258 Chinese Han schizophrenic parent-proband trios. There was significant transmission disequilibrium in allelic transmission of C, A, T from rs221533, 433E1006, rs3924999 loci, respectively (rs221533, 433E1006, rs3924999). Haplotype was analyzed at frequency exceeding $1 \%$. In 3-marker-haplotype, C/C/G and C/C/A (rs221533, rs7820838, 433E1006) transmitted predominantly. In 4-marker-haplotype (rs221533, rs7820838, 433E1006, rs3924999), C/C/G/T, C/C/A/C, and C/C/A/T showed transmission disequilibrium. According to these studies, the NRGl gene polymorphism is significantly associated with SCZ in Chinese Han, especially in the positive subtype of SCZ [90].

Linkage studies have implicated 10q22-q23 as a SCZ susceptibility locus in Ashkenazi Jewish (AJ) and Han Chinese from Taiwan populations. Chen et al. [91] performed a peakwide association fine mapping study by using 1414 SNPs across approximately 12.5 Mb in 10q22-q23 of Ashkenazi Jewish, and found strong evidence of association by using the "delusion" factor as the quantitative trait at 3 SNPs (rs10883866, rs10748842, and rs6584400) located in a $13 \mathrm{~kb}$ interval in intron 1 of $N R G 3$. NRG3 is primarily expressed in the CNS and is 1 of 3 paralogs of NRG1 [91].

\section{Neurogranin (NRGN)}

A marker located 3457 bases upstream of the NRGN gene on $11 \mathrm{q} 24.2$ (rs128078009-T) has been associated with SCZ [92]. This marker has an average risk allele control frequency of $83 \%$. Another NRGN SNP (rs7113041) has been reported to be associated with SCZ in Portuguese patients [93]. Altered NRGN activity might mediate the effects of NMDA hypofunction implicated in SCZ pathogenesis [92].

\section{Reelin (RELN)}

RELN is a large secreted protein of the extracellular matrix that has been proposed to participate to the etiology of SCZ. The RELN gene encodes a secretory glycoprotein critical for brain development and synaptic plasticity. Postmortem studies have shown lower RELN protein levels in the brains of patients with SCZ and BP compared with controls. In a genome-wide association study of $\mathrm{SCZ}$, the strongest association was found in a marker within RELN, although this association was seen only in women. RELN is also associated with BP in women [94]. There is association between RELN intragenic STR allele and working memory, impaired cognitive functioning, and more severe positive and negative symptoms of SCZ [95]. RELN plays a pivotal role in neurodevelopment. Excessive RELN promoter methylation and/or decreased RELN gene expression have been described in SCZ and autism. Temporocortical tissue (Brodmann Area 41/42) of postpuberal individuals are heavily methylated, especially at $\mathrm{CpG}$ positions located between -131 and $-98 \mathrm{bp}$. Sex hormones thus seemingly boost DNA methylation at the RELN promoter. This physiological mechanism might contribute to the onset of SCZ and the worsening of autistic behaviors during the puberal period [96]. During development, RELN is crucial for the correct cytoarchitecture of laminated brain structures and is produced by a subset of neurons named
Cajal-Retzius. After birth, most of these cells degenerate and RELN expression persists in postnatal and adult brain. In hippocampal cultures, RELN is secreted by GABAergic neurons displaying an intense RELN immunoreactivity (IR). Secreted RELN binds to receptors of the lipoprotein family on neurons with a punctate RELN IR. Blocking protein secretion rapidly and reversibly changes the subunit composition of $\mathrm{N}$-methyl-D-aspartate glutamate receptors (NMDARs) to a predominance of NR2B-containing NMDARs. Addition of recombinant or endogenously secreted RELN rescues the effects of protein secretion blockade and reverts the fraction of NR2B-containing NMDARs to control levels. The continuous secretion of RELN is necessary to control the subunit composition of NMDARs in hippocampal neurons. Defects in RELN secretion could play a major role in the development of neuropsychiatric disorders, particularly those associated with deregulation of NMDARs such as SCZ [97]. RELN is downregulated in the brain of schizophrenic patients and of heterozygous reeler mice $(\mathrm{rl} /+)$. The behavioral phenotype of $r l$ - mice, however, matches only partially the SCZ hallmarks. Homozygous reeler mutants $(r l / r l)$ exhibit reduced density of parvalbumin-positive (PV+) GABAergic interneurons in anatomically circumscribed regions of the neostriatum. The striatal regions in which $r l / r l$ mice exhibited decreased density of PV+ interneurons are either unaltered (rostral striatum) or equally altered (dorsomedial and ventromedial intermediate striatum, caudal striatum) in $\mathrm{rl} / \mathrm{+}$ mice. RELN haploinsufficiency alters the density of PV+ neurons in circumscribed regions of the striatum and selectively disrupts behaviors sensitive to dysfunction of these targeted regions [98]. Brain abnormalities in $+/ r l$ are similar to psychotic brain and include a reduction in glutamic acid de carboxylase 67 (GAD67), dendritic arbors and spine density in cortex and hippocampus, and abnormalities in synaptic function including long-term potentiation (LTP). RELN and GAD67 promoters are hypermethylated in GABAergic neurons of psychotic postmortem brain and DNA methyltransferase 1 (DNMT1) is upregulated. Hypermethlyation of RELN and GAD67 promoters can be induced by treating mice with methionine, and these mice display brain and behavioral abnormalities similar to $+/ r l$. $[99,100]$.

\section{Serotonin (5-Hydroxytryptamine [5-HT]) Transporter (SLC6A4)}

SLC6A4 is known to influence mood, emotion, cognition, and efficacy of antidepressants, particularly that of selective serotonin reuptake inhibitors. Atypical antipsychotics exert their effects partially through serotonergic systems, and hence, variation in 5-HT uptake may affect antipsychotic action mediated through the serotonergic system. The genetic roles of 5 polymorphisms of SLC6A4, including those of the widely studied $44 \mathrm{bp}$ VNTR in the promoter region of SLC6A4 (the serotonin transporter gene-linked polymorphic region: 5HTTLPR) and a VNTR polymorphism (STin2) in the second intron, have been studied in SCZ. Significant allelic and genotypic associations with rs2066713, 5HTTLPR, and STin2 polymorphisms have been detected. A haplotype linking these three risk alleles, 5HTTLPR/S-rs2066713/C-STin2/12-repeat, was also significantly associated with disease in a South Indian population [101] 


\section{SMARCA2/BRM and the SWI/SNF Chromatin-Remodeling Complex}

Chromatin remodeling may play a role in the neurobiology of SCZ. The SMARCA2 gene encodes BRM in the SWI/SNF chromatin-remodeling complex, and associations of SNPs with SCZ were found in two linkage disequilibrium blocks in the SMARCA2 gene after screening of 11,883 SNPs (rs2296212) and subsequent screening of 22 genes involved in chromatin remodeling (rs3793490) in a Japanese population. A risk allele of a missense polymorphism (rs2296212) induced a lower nuclear localization efficiency of BRM, and risk alleles of intronic polymorphisms (rs3763627 and rs3793490) were associated with low SMARCA2 expression levels in the postmortem prefrontal cortex. A significant correlation in the fold changes of gene expression from schizophrenic prefrontal cortex was seen with suppression of SMARCA2 in transfected human cells by specific siRNA, and of orthologous genes in the prefrontal cortex of Smarca2 knockout mice. Smarca2 knockout mice showed impaired social interaction and prepulse inhibition. Psychotogenic drugs lowered Smarca2 expression while antipsychotic drugs increased it in the mouse brain. According to Koga et al. [102] these findings support the role of BRM in the pathophysiology of SCZ [102].

\section{TAPASIN}

Chlamydiaceae species has been identified as a major factor in the pathogenesis of SCZ, suggesting defective immune responses of schizophrenic patients against this environmental factor. Immune responses against Chlamydiaceae species are controlled by immunogenetic factors. Successful responses against microbes depend on the presentation of immunogenic peptides by HLA molecules, which are encoded by a highly polymorphic gene system. Several HLA alleles or HLA antigens have been found associated with SCZ in some studies. It has been proposed that variants of these genes, which control transportation and loading of microbial peptides onto HLA molecules, could prevent clearing of immune cell infection by selection of nonimmunogenic peptides for HLA presentation. To generate support for this hypothesis Fellerhoff and Wank [103] determined in a small group of schizophrenic patients and control individuals allele frequencies of the transporter proteins TAP1/TAP2, which select the immunoproteasometailored peptides for transportation. Frequencies of TAPASIN alleles, which encode chaperons and also may select peptides for loading on MHC molecules have also been studied, and significant associations between SCZ and TAP1 allele frequencies as well as TAPASIN allele frequencies were found, suggesting that variants of these two genetic systems could influence SCZ. These genes belong to the family of $\mathrm{ABC}$ transporter proteins and may also influence the efficiency of drugs [103].

\section{TATA Box-Binding Protein Gene (TBP)}

Spinocerebellar ataxia type 17 (SCA17) is a rare autosomal dominant neurodegenerative disorder with ataxia and psychotic symptoms. SCA17 is caused by an expanded polyglutamine tract in the TATA box-binding protein (TBP) gene. Ohi et al. [104] investi- gated the association between SCZ and CAG repeat length in common TBP alleles with fewer than 42 CAG repeats in a Japanese population. Higher frequency of alleles with greater than 35 CAG repeats was found in patients with SCZ compared with that in controls. A negative correlation between the number of CAG repeats in the chromosome with longer CAG repeats out of 2 chromosomes and age at onset of SCZ was also observed. TBP genotypes with greater than 35 CAG repeats, which were enriched in patients with SCZ, were significantly associated with hypoactivation of the prefrontal cortex measured by near-infrared spectroscopy during the tower of Hanoi, a task of executive function. These findings suggest possible associations of the genetic variations of the TBP gene with risk for SCZ, age at onset and prefrontal function [104].

\section{Transcription Factor 4 (TFC4)}

A marker in intron 4 of the transcription factor 4 (TFC4) on 18q21.2 (rs9960767-C) has been associated with SCZ [85]. The risk allele control frequency of this marker is about $6 \%$. TCF4 is essential for normal brain development. Mutations in this gene were found to be responsible for Pitt-Hopkins syndrome, an autosomaldominant neurodevelopmental disorder characterized by mental and psychomotor retardation, microcephaly, epilepsy, and facial dysmorphism.

\section{Tripartite Motif Protein 32 (TRIM32)}

Mutations in the gene encoding tripartite motif protein 32 (TRIM32) cause two seemingly diverse diseases: limb-girdle muscular dystrophy type $2 \mathrm{H}$ (LGMD2H) or sarcotubular myopathy (STM) and Bardet-Biedl syndrome type 11 (BBS11). TRIM32 is involved in protein ubiquitination, acting as a widely expressed ubiquitin ligase that is localized to the Z-line in skeletal muscle. TRIM 32 binds and ubiquitinates dysbindin, a protein implicated in the genetic aetiology of SCZ, augmenting its degradation. Smallinterfering RNA-mediated knock down of TRIM32 in myoblasts resulted in elevated levels of dysbindin. The LGMD2H/STMassociated TRIM32 mutations, D487N, and R394H, impair ubiquitin ligase activity toward dysbindin and were mislocalized in heterologous cells. These mutants were able to self-associate and also coimmunoprecipitated with wild-type TRIM32 in transfected cells. D487N mutant could bind to both dysbindin and its E2 enzyme but was defective in monoubiquitination. The BBS11 mutant P130S did not show any biochemical differences compared with the wild-type protein. TRIM32 is a regulator of dysbindin and LGMD2H/STM mutations may impair substrate ubiquitination [105].

\section{Tyrosine 3-monooxygenase/Tryptophan 5-monooxygenase Activation Protein, Eta Isoform (YWHAH)}

Brain protein 14-3-3, eta isoform, or tyrosine 3monooxygenase/tryptophan 5-monooxygenase activation protein 1 (YWHAl; 14-3-3-ETA) is a protein kinase-dependent 
activator of tyrosine and tryptophan hydroxylases and an endogenous inhibitor of protein kinase C. The 14-3-3 protein exists in several distinct forms: for example, beta (YWHAB), gamma (YWHAG), epsilon (YWHAE), zeta (YWHAZ), theta (YWHAQ), sigma (SFN), and eta (YWHAH). YWHAH (22q12) is a positional and functional candidate gene for both SCZ and BP. This gene has been previously shown to be associated with both disorders, and the chromosome location (22q12.3) has been repeatedly implicated in linkage studies for these disorders. It codes for the eta subtype of the 14-3-3 protein family, is expressed mainly in brain, and is involved in HPA axis regulation. Five tag SNPs and the (GCCTGCA)n polymorphic locus present in this gene have been genotyped and the rs2246704 SNP was associated with BP and psychotic BP. The polymorphic repeat and two other SNPs were also modestly associated with psychotic BP [106].

\section{Vesicular Monoamine Transporters (VMAT1/SLC18A1)}

Vesicular monoamine transporters (VMATl and VMAT2) mediate accumulation of monoamines such as serotonin, dopamine, adrenaline, and noradrenaline from the cytoplasm into storage organelles in monoaminergic neurons. VMATl is preferentially expressed in neuroendocrine cells and VMAT2 is primarily expressed in the CNS. The VMAT1 gene (SLC18A1) is a locus with strong evidence of linkage with SCZ and, thus, the polymorphic forms of the VMAT1 gene may confer susceptibility to SCZ [107]. The vesicular monoamine transporter 1 gene (VMAT1/SLC18A1) maps to the shared $\mathrm{BD} / \mathrm{SCZ}$ susceptibility locus on chromosome 8p21. Variations in the VMAT1 gene might affect transporter function and/or expression, and might be involved in the etiology of SCZ. Genotypes of 62 patients with SCZ and 188 control subjects of European descent were obtained for 4 missense SNPs (Thr4Pro, Thr98Ser, Thr136Ile, Val392Leu) and 2 noncoding SNPs (rs988713, rs2279709) [108,109]. The previously reported association of Pro4Thr of the VMAT1 gene with SCZ could not be replicated; however, evidence was obtained for a possible role of the Thr98Ser in giving susceptibility to SCZ in women [110].

\section{X-ray Repair Complementing Defective Repair in Chinese Hamster Cells 1 (XRCC1)}

Human cells fused with Chinese hamster ovary (CHO) mutant lines, defective at different genes for excision repair of DNA following ultraviolet (UV) irradiation or defective in repair following $\mathrm{X}$-irradiation, produce hybrids that retain the human gene that complements the defect in the CHO line when selected under conditions that require repair. The 1893-bp open reading frame of this gene encodes a protein of 631 amino acids, compared with the 633-amino acid polypeptide of human XRCC1, which shares $86 \%$ sequence identity with mouse proteins. Association between genetic polymorphism of XRCC1 Arg 194Trp and risk of SCZ has been reported [111].

\section{Zinc Finger Protein 804A (ZNF804A)}

Two recent genome-wide association studies reported association between SCZ and the ZNF804A gene on chromosome 2q32.1 (rs1344706, rs7597593, rs1344706) [112,113].

\section{Pharmacogenomics of Neuroleptics}

Historically, the vast majority of pharmacogenetic studies of CNS disorders have been addressed to evaluate the impact of cytochrome P450 enzymes on drug metabolism. Conventional targets for psychotropic drugs were the neurotransmitters dopamine, serotonin, noradrenaline, GABA, ion channels, acetylcholine and their respective biosynthetic and catalyzing enzymes, receptors, and transporters [114]. In the past few years many different genes have been associated with both pathogenesis and pharmacogenomics of neuropsychiatric disorders. Some of these genes and their products constitute potential targets for future treatments. New developments in genomics, including whole genome genotyping approaches and comprehensive information on genomic variation across populations, coupled with large-scale clinical trials in which DNA collection is routine, now provide the impetus for a next generation of pharmacogenetic studies and identification of novel candidate drugs [115-117].

Pharmacogenomics relates to the application of genomic technologies, such as genotyping, gene sequencing, gene expression, genetic epidemiology, transcriptomics, proteomics, metabolomics, and bioinformatics, to drugs in clinical development and on the market, applying the large-scale systematic approaches of genomics to speed up the discovery of drug response markers, whether they act at the level of drug target, drug metabolism, or disease pathways $[4,10-12,118]$. The final aim of pharmacogenomics is therapeutics optimization and personalized pharmacotherapy $[3,4,6]$.

The pharmacogenomic outcome depends upon many different determinant factors including (1) genomic profile, (2) disease phenotype, (3) concomitant pathology, (4) genotype-phenotype correlations, (5) nutritional conditions, (6) age and gender, (7) pharmacological profile of drugs, (8) drug-drug interactions, (9) gene expression profile, (10) transcriptomic cascade, (11) proteomic profile, and (12) metabolomic networking. The dissection and further integration of all these factors is of paramount importance for the assessment of the pharmacogenomic outcome in terms of safety and efficacy [4].

\section{Cytochrome P450-Related Pharmacogenetics}

Drug metabolism includes phase I reactions (i.e., oxidation, reduction, hydrolysis) and phase II conjugation reactions (i.e., acetylation, glucuronidation, sulphation, methylation). The principal enzymes with polymorphic variants involved in phase I reactions are the following: CYP3A4/5/7, CYP2E1, CYP2D6, CYP2C19, CYP2C9, CYP2C8, CYP2B6, CYP2A6, CYP1B1, CYP1A1/2, epoxide hydrolase, esterases, NQO1 (NADPH-quinone oxidoreductase), DPD (dihydropyrimidine dehydrogenase), ADH (alcohol dehydrogenase), and ALDH (aldehyde dehydrogenase). Major enzymes involved in phase II reactions include the following: UGTs 
(uridine $5^{\prime}$-triphosphate glucuronosyl transferases), TPMT (thiopurine methyltransferase), COMT , HMT (histamine methyltransferase), STs (sulfotransferases), GST-A (glutathion Stransferase A), GST-P, GST-T, GST-M, NAT2 (N-acetyl transferase), NAT1, and others [3-5,11].

The typical paradigm for the pharmacogenetics of phase I drug metabolism is represented by the cytochrome P-450 enzymes, a family of microsomal drug-metabolizing enzymes. P450 enzymes comprise a superfamily of heme-thiolate proteins widely distributed in bacteria, fungi, plants, and animals. The P450 enzymes are encoded in genes of the CYP superfamily and act as terminal oxidases in multicomponent electron transfer chains, which are called P450-containing monooxigenase systems. Some of the enzymatic products of the CYP gene superfamily can share substrates, inhibitors, and inducers whereas others are quite specific for their substrates and interacting drugs.

The microsomal, membrane-associated, P450 isoforms CYP3A4, CYP2D6, CYP2C9, CYP2C19, CYP2E1, and CYP1A2 are responsible for the oxidative metabolism of over $90 \%$ of marketed drugs. About $60-80 \%$ of the psychotropic agents currently used for the treatment of neuropsychiatric disorders are metabolized via enzymes of the CYP family, especially CYP1A2, CYP2B6, CYP2C8/9, CYP2C19, CYP2D6, and CYP3A4 (Table 3). CYP3A4 metabolizes more drug molecules than all other isoforms together. Most of these polymorphisms exhibit geographic and ethnic differences [119-122]. These differences influence drug metabolism in different ethnic groups in which drug dosage should be adjusted according to their enzymatic capacity, differentiating normal, or extensive metabolizers (EMs), intermediate metabolizers (IMs), poor metabolizers (PMs), and ultrarapid metabolizers (UMs). Approximately $20-30 \%$ of CNS drugs are metabolized by CYP2D6 enzymes, which are deficient in $10-20 \%$ of Caucasians. Only $26 \%$ of Southern Europeans are pure EMs for the trigenic cluster integrated by CYP2D6+CYP2C19+CYP2C9 variants, indicating that by trial-and-error only one-quarter of the population might be good responders to the conventional drugs of current prescription worldwide $[3,4,6,123]$.

Most drugs act as substrates, inhibitors, or inducers of CYP enzymes. There are substantial differences between individuals in the effects of psychotropic drugs in the treatment of neuropsychiatric disorders. Pharmacogenetic studies of psychotropic drug response have focused on determining the relationship between variation in specific candidate genes and the positive and adverse effects of drug treatment $[114,124,125]$. Approximately, 18\% of neuroleptics are major substrates of CYP1A2 enzymes, $40 \%$ of CYP2D6, and $23 \%$ of CYP3A4 (Table 3); $24 \%$ of antidepressants are major substrates of CYP1A2 enzymes, 5\% of CYP2B6, 38\% of CYP2C19, $85 \%$ of CYP2D6, and $38 \%$ of CYP3A $4 ; 7 \%$ of benzodiazepines are major substrates of CYP2C19 enzymes, $20 \%$ of CYP2D6, and $95 \%$ of CYP3A4 $[3,4]$. About $80 \%$ of patients with resistant depression, $60 \%$ of patients nonresponsive to neuroleptics, and $50-70 \%$ of patients with paradoxical responses to benzodiazepines are carriers of mutant variants of the CYP2D6, CYP2C9, and CYP3A4 genes, falling within the categories of poor or ultra-rapid metabolizers [4].

The impaired metabolic capacity of the CYP2D6-PM genotype results in higher steady-state plasma concentrations at a given dose, thus increasing the risk of toxic effects from medication. Extrapyramidal syndrome or TD (EPS/TD) is significantly more frequent among PM patients than among the matched IM and EM control subjects. [126].

Risperidone is converted to 9-hydroxyrisperidone by CYP2D6. The CYP2D6*10 polymorphism, which is a prevalent mutant allele among East Asians, and the presence of comedication, exert significant influences on the pharmacokinetics of risperidone [127]. The plasma levels of risperidone and 9-OH-risperidone are significantly different among CYP2D6 genotype groups. CYP3A5 nonexpressors exhibit higher plasma concentrations of both risperidone and 9-OH-risperidone than its expressors [128].

\section{Drug- and Disease-Related Pharmacogenomics}

Targets that show promise for pharmacologic focus in SCZ include the dopamine receptors in the prefrontal cortex, the serotonin receptors in the prefrontal cortex, and anterior cingulate cortex, the glutamatergic excitatory synapse, the acetylcholine nicotinic receptors in the hippocampus, the acetylcholine muscarinic receptors, and the brain GABA system $[129,130]$. In addition to Cytochrome P450 enzymes, many other gene products influence both efficacy and safety of psychotropic drugs [3,4,114,117,131-133].

Analysis of polymorphic variants in 5-HT2A receptors (5HT2AR-A-1438G) revealed that schizophrenic carriers of the G/G genotype receiving olanzapine showed a significant tendency toward improvement in the PANSS positive syndrome score in comparison with patients who did not have a $G$ gene (AA and AG) [134].

Aripiprazole acts as a partial agonist at dopamine D2 (DRD2) and D3 (DRD3) and serotonin 1A (HTR1A) receptors and as an antagonist at serotonin 2A receptors (HTR2A) [135]. Since aripiprazole acts as an antagonist at HTR2A, genetic variants of HTR2A may be important in explaining variability in response to aripiprazole. The GG/CC genotype group of HTR2A A-1438G/T102C polymorphisms predicts poor aripiprazole response specifically for negative symptoms. In addition, the clinical factors, including dosage of aripiprazole, age, duration of illness, and diagnostic subtype, were found to influence Positive and Negative Syndrome Scale (PANSS) performance after aripiprazole treatment [136]. Aripiprazole was associated with increased $B D N F$ promoter activity. Treatment with aripiprazole at $10 \mu \mathrm{M}$ increased the levels of BDNF by $85 \%$, compared with control levels, whereas haloperidol had no effect. Cells treated with aripirazole effectively increased the levels of GSK-3beta phosphorylation and Bcl-2 at doses of 5 and $10 \mu \mathrm{M}$ (30 and 58 and 31 and $80 \%$, respectively); however, haloperidol had no effects on p-GSK-3 beta and Bcl-2 expression [137].

The prototypical atypical antipsychotic agent, clozapine (CLZ), is more efficacious for refractory SCZ than the "typical" antipsychotics. Since 2002, at least 22 association studies have shown that the DTNBP1 can be associated with the risk for $\mathrm{SCZ}$, and it has also been hypothesized that DTNBP1 might influence the response to antipsychotic treatments. Patients with diplotype ACCCTC/GTTGCC, genotypes $\mathrm{T} / \mathrm{T}+\mathrm{T} / \mathrm{C}$, or allele $\mathrm{T}$ of marker rs742105 (P1333) have better response to CLZ, and 
Table 3. Neuroleptics metabolized via enzymes of the CYP gene family and other gene-related enzymes $[4,15,161,162]$

\begin{tabular}{|c|c|c|c|c|c|}
\hline Drugs & $\begin{array}{l}\text { Pharmacological } \\
\text { category }\end{array}$ & Major substrate & Minor substrate & Inhibitors & Other genes \\
\hline Aripiprazole & Atypical antipsychotic & CYP2D6, CYP3A4 & & & $\begin{array}{l}\text { ADRA1A, DRD2, DRD3, HTR1A, } \\
\text { HTR2A, HTR2C }\end{array}$ \\
\hline Benperidol & Neuroleptic antipsychotic & & & & DRD2 \\
\hline Bromperidol & $\begin{array}{l}\text { Antipsychotic, } \\
\text { neuroleptic } \\
\text { butyrophenone }\end{array}$ & & & & $A B C B 1, H T R 2, D R D 2$ \\
\hline Chlorpromazine & $\begin{array}{l}\text { Phenothiazine } \\
\text { antipsychotic }\end{array}$ & CYP2D6 & CYP1A2, CYP3A4 & CYP2D6, CYP2E1 & $\begin{array}{l}A B C B 1, A C A C A, A D R A 1, B D N F \\
D R D 2, D R D 3, H T R 2 C, K C N E 2, \\
\text { LEP, NPY, SCN5A }\end{array}$ \\
\hline Clozapine & Atypical antipsychotic & CYP1A2 & $\begin{array}{l}\text { CYP2A6, CYP2C8/9, } \\
\text { CYP2C19, CYP2D6, } \\
\text { CYP3A4 }\end{array}$ & $\begin{array}{l}\text { CYP1A2, CYP2C8/9, } \\
\text { CYP2C19, CYP2D6, } \\
\text { CYP2E1, CYP3A4 }\end{array}$ & $\begin{array}{l}\text { ADRA1, ADRB3, APOA5, APOD, } \\
\text { APOC3, DRD2, DRD3, DRD4, } \\
\text { GNB3, GNAS1, HLAA1, HRH1, } \\
\text { HRH2, HTR1A, HTR2A, HTR2C, } \\
\text { HTR6, RGS2, SLC6A2, SLC6A4, } \\
\text { TNF-A }\end{array}$ \\
\hline Droperidol & Atypical antipsychotic & & & & $\begin{array}{l}\text { ADRA1,DRD2, KCNE2, KCNH, } \\
\text { SCN5A }\end{array}$ \\
\hline Fluphenazine & $\begin{array}{l}\text { Typical antipsychotic } \\
\text { phenothiazine }\end{array}$ & CYP2D6 & & $\begin{array}{l}\text { CYP1A2, CYP2C9, } \\
\text { CYP2D6, CYP2E1 }\end{array}$ & $D R D 1, D R D 2$ \\
\hline Flupenthixol & Typical antipsychotic & & & & DRD1 \\
\hline Haloperidol & Typical antipsychotic & CYP2D6, CYP3A4 & CYP1A2 & CYP2D6, CYP3A4 & $\begin{array}{l}\text { ABCB1, ADR1A, DRD1, DRD2, } \\
\text { DRD4, DTNBP1, GRIN2B, } \\
\text { HTR2A, IL1RN, KCNE2, SCN5A }\end{array}$ \\
\hline Loxapine & Typical antipsychotic & & & & $\begin{array}{l}\text { ADR1A, DRD1, DRD2, } \\
\quad H T R 2 A,, \text { KCNE2, SCN5A }\end{array}$ \\
\hline Mesoridazine & Typical antipsychotic & & & & ADR1A, DRD2, KCNE2, SCN5A \\
\hline Molindone & Typical antipsychotic & & & & ADRA1, DRD2 \\
\hline Olanzapine & Atypical antipsychotic & CYP1A2 & CYP1A2, CYP2D6 & $\begin{array}{l}\text { CYP1A2, CYP2C8/9, } \\
\text { CYP2C19, CYP2D6, } \\
\text { CYP3A4 }\end{array}$ & $\begin{array}{l}\text { ABCB1, ADRA1, ADRB3, APOA5, } \\
\text { APOC3, COMT, DRD2, DRD3, } \\
\text { GNB3, GRM3, HRH1, HRH2, } \\
\text { HTR2A, HTR2C, HTR6, LEP, } \\
\text { LEPR, LPL, RGS2, SLC6A2, } \\
\text { TNF-A }\end{array}$ \\
\hline Paliperidone & Atypical antipsychotic & & & & $\begin{array}{l}\text { ADRA1A, ADRA1B, ADRA1D, } \\
\text { DRD2, HRH1, HTR2A, }\end{array}$ \\
\hline Perphenazine & $\begin{array}{l}\text { Typical antipsychotic } \\
\text { phenothiazine }\end{array}$ & CYP2D6 & $\begin{array}{l}\text { CYP1A2, CYP2C8/9, } \\
\text { CYP2C19, CYP3A4 }\end{array}$ & CYP1A2, CYP2D6 & $A D R A 1 A, D R D 1, D R D 2, D R D 3$ \\
\hline Periciazine & $\begin{array}{l}\text { Typical, antipsychotic } \\
\text { phenothiazine, } \\
\text { piperidine }\end{array}$ & CYP2D6, CYP3A4 & & & $D R D 1, D R D 2$ \\
\hline Pimozide & Typical antipsychotic & CYP1A2, СYP3A4 & & $\begin{array}{l}\text { CYP2C19, CYP2D6, } \\
\text { CYP2E1, CYP3A4 }\end{array}$ & $\begin{array}{l}\text { ADRA1A, DRD2, KCNE1, KCNE2, } \\
\text { KCNQ1, KCNH2, SCN5A }\end{array}$ \\
\hline Pipotiazine & Typical antipsychotic & CYP2D6, CYP3A4 & & & $D R$ \\
\hline Prochlorperazine & Typical antipsychotic & & & & $A D R A 1 A, A B C B 1, D R D 2$ \\
\hline Quetiapine & Atypical antipsychotic & CYP3A4 & CYP2D6 & & $\begin{array}{l}\text { ADRA1A, DRD1, DRD2, HRH1, } \\
\text { HTR1A, HTR2A, HTR2B, } \\
\text { KCNE1, KCNE2, KCNH2, } \\
\text { KCNQ1, SCN5A }\end{array}$ \\
\hline Risperidone & Atypical antipsychotic & CYP2D6 & CYP2A4 & CYP2D6, CYP3A4 & $\begin{array}{l}\text { ABCB1, ADRA1A, ADRA1B, } \\
\text { DRD2, DRD3, DRD4, HTR1A, } \\
\text { HTR2A, HTR2C, KCNE2, RGS2, } \\
\text { SLC6A2, SCN5A }\end{array}$ \\
\hline Sulpiride & Atypical antipsychotic & & & & DRD2 \\
\hline Thioridazine & $\begin{array}{l}\text { Typical antipsychotic } \\
\text { phenothiazine }\end{array}$ & CYP2D6 & CYP2C19 & $\begin{array}{l}\text { CYP1A2, CYP2C8/9, } \\
\text { CYP2D6, CYP2E1 }\end{array}$ & ADRA1A, DRD2, KCNE2, SCN5A \\
\hline
\end{tabular}


Table 3. Continued

\begin{tabular}{|c|c|c|c|c|c|}
\hline Drugs & $\begin{array}{l}\text { Pharmacological } \\
\text { category }\end{array}$ & Major substrate & Minor substrate & Inhibitors & Other genes \\
\hline Thiothixene & Typical antipsychotic & CYP1A2 & & CYP2D6 & $\begin{array}{l}\text { ADRA1A, DRD2, KCNE2, KCNQ1, } \\
\text { KCNH6, SCN5A, }\end{array}$ \\
\hline Trifluoperazine & $\begin{array}{l}\text { Typical antipsychotic } \\
\text { phenothiazine }\end{array}$ & CYP1A2 & & & $A D R A 1 A, D R D 2$ \\
\hline Ziprasidone & Atypical antipsychotic & & CYP1A2, СYP3A4 & CYP2D6, CYP3A4 & $\begin{array}{l}\text { ADRA1, AOX1, DRD2, DRD3, } \\
\text { HTR2C, HTR1A, HTR2A, } \\
\text { KCNE2, KCNH2, RGS4, SCN5A }\end{array}$ \\
\hline Zonisamide & Anticonvulsant & СYР3A4 & CYP2C19 & & \\
\hline Zuclopenthixol & Typical antipsychotic & CYP2D6 & & & $\begin{array}{l}\text { ADRA1, DRD1, DRD2, KCNE2, } \\
\text { SCN5A }\end{array}$ \\
\hline
\end{tabular}

ABCB1, ATP-binding cassette, sub-family B (MDR/TAP), member 1; ACACA, Acetyl-Coenzyme A carboxylase alpha; ADRA1, Adrenergic, alpha-1 receptor; $A D R A 1 A$, Adrenergic, alpha-1A-, receptor; ADRA1B, Adrenergic, alpha-1B-, receptor; ADRB3, Adrenergic, beta-3-, receptor; ADRA1D, Adrenergic, alpha-1D-, receptor; AOX1, Aldehyde oxidase 1; APOA5, Apolipoprotein A-V; APOC3, Apolipoprotein C-III; APOD, Apolipoprotein D; BDNF, Brain-derived neurotrophic factor; COMT, Catechol-O-methyltransferase; CYP1A2, Cytochrome P450, family 1, subfamily A, polypeptide 2; CYP2A6, Cytochrome P450, family 2, subfamily A, polypeptide 6; CYP2C19, Cytochrome P450, family 2, subfamily C, polypeptide 19; CYP2C8, Cytochrome P450, family 2, subfamily C, polypeptide 8; CYP2C9, Cytochrome P450, family 2, subfamily C, polypeptide 9; CYP2D6, Cytochrome P450, family 2, subfamily D, polypeptide 6; CYP2E1, Cytochrome P450, family 2, subfamily E, polypeptide 1; CYP3A4, Cytochrome P450, family 3, subfamily A, polypeptide 4; DR, Dopamine receptor; DRD1, Dopamine receptor D1; DRD2, Dopamine receptor D2; DRD3, Dopamine receptor D3; DRD4, Dopamine receptor D4; DTNBP1, Dystrobrevin binding protein 1; GNAS, GNAS complex locus; GNB3, Guanine nucleotide binding protein (G protein), beta polypeptide 3; GRIN2B, Glutamate receptor, ionotropic, N-methyl D-aspartate 2B; GRM3, Glutamate receptor, metabotropic 3; HLA, Major histocompatibility complex; HRH1, Histamine receptor H1; HRH2, Histamine receptor H2; HTR1A, 5-Hydroxytryptamine (serotonin) receptor 1A; HTR2A, 5-Hydroxytryptamine (serotonin) receptor 2A; HTR2B, 5-Hydroxytryptamine (serotonin) receptor 2B; HTR2C, 5-Hydroxytryptamine (serotonin) receptor 2C; HTR6, 5-Hydroxytryptamine (serotonin) receptor 6; IL1RN, Interleukin 1 receptor antagonist; KCNE1, Potassium voltage-gated channel, Isk-related family, member $1 ; K C N E 2$, Potassium voltage-gated channel, Isk-related family, member 2; KCNH, Potassium voltage-gated channel, subfamily $\mathrm{H}$ (eag-related), member 1-8; KCNH2, Potassium voltage-gated channel, subfamily $\mathrm{H}$ (eag-related), member 2; KCNH6, Potassium voltage-gated channel, subfamily H (eag-related), member 6; KCNQ1, Potassium voltage-gated channel, KQT-like subfamily, member 1; LEP, Leptin; LEPR, Leptin receptor; LPL, Lipoprotein lipase; NPY, Neuropeptide Y; RGS2, Regulator of G-protein signaling 2, 24kDa; RGS4, Regulator of G-protein signaling 4; SCN5A, Sodium channel, voltage-gated, type $V$, alpha subunit; SLC6A2, Solute carrier family 6 (neurotransmitter transporter, noradrenalin), member 2; SLC6A4, Solute carrier family 6 (neurotransmitter transporter, serotonin), member 4; TNF, Tumor necrosis factor (TNF superfamily, member 2).

patients with diplotype ACCCTC/GCCGCC, genotype A/G, or allele A of marker rs909706 (P1583) have better response to haloperidol in European-Americans, African-Americans, and/or the combined sample. European-American patients with diplotype ACCCTC/GCCGCC have worse response to CLZ on positive symptoms. These results might indicate that DTNBP1 gene modulates the effects of both the atypical antipsychotic CLZ and the typical antipsychotic haloperidol and that SCZ patients with different DTNBPl diplotypes, haplotypes, genotypes, or alleles might have different responses to these antipsychotics [138].

Disruption of the RELN and GABAergic signaling systems have been observed in psychiatric disorders including autism, SCZ, BD, and major depression. Chronic administration of psychotropic medications (CLZ, fluoxetine, haloperidol, lithium, olanzapine, and valproic acid) used in the treatment of psychiatric disorders alters levels of RELN, its receptor Vldlr, downstream molecules Gsk3 beta, Dab-1, and Gad65/67 in the prefrontal cortex. mRNAs for RELN, Vldlr, Dab-1, Gsk3 beta, and Gad65 were each significantly altered by at least one of the drugs tested, and in the case of RELN, $D a b-1$, and Gsk3 beta, by multiple drugs, suggesting that the RELN signaling and GABAergic systems are affected by commonly used psychotropic medications [139]. Valproic acid facilitates chromatin remodeling when it is associated with CLZ or sulpiride but not with haloperidol or olanzapine. This remodeling might contribute to RELN - and GAD67-promoter demethylation and might reverse the GABAergic-gene-expression downregulation associated with SCZ morbidity [140].

Flavin-containing monooxygenase 3 (FMO3) genotype data for European-, Latin-, African-, and Asian-American SCZ patients treated with olanzapine were compared to age-, gender-, and race/ethnicity-matched controls. For European Americans, significant differences in individual cases versus controls were observed between FMO3 158 and 257 alleles and genotype frequencies and SCZ delusions, hallucinations, and weight gain/increased appetite. For Latin Americans, a significant difference in individual cases versus controls was observed for FMO3 158 and 257 for SCZ delusions as well as hallucinations and delusions. Sleepiness and weight gain were associated with allele 308. In African-Americans, a comparison of allele frequency and diagnosis showed a significant dependence on allele 158 in individual cases versus controls [141].

Haplotype analysis showed highly significant association of 7 COMT marker haplotypes with SCZ, and allelic associations of two SNPs (rs4633, rs4680) with drug response were also found. A 
significant association of markers located between intron 1 and intron 2 (rs737865, rs6269), and in exon 4 (rs4818, rs4680) with drug response was detected, indicating that the interacting effects within the COMT gene polymorphisms may influence the disease status and response to neuroleptics in SCZ patients [142].

Olanzapine is a second-generation antipychotic that may cause weight gain and metabolic syndrome in some cases. The peroxisome proliferator-activated receptor (PPAR)-gamma is an important gene in the progress of type II diabetes and metabolic syndrome. Significant differences were found between pretreatment and posttreatment body mass index (BMI) and weight change in Prol2Ala polymorphism of PPARG2 in Turkish patients [143].

Twenty-one loci of diverse candidate genes encoding dopamine, serotonin (5-HT), histamine, and adrenergic receptors, tumor necrosis factor-alpha, ghrelin, adiponectin, and PPARG2, were analyzed as candidate genes for olanzapine-related body weight gain. Olanzapine-induced weight gain correlated negatively with baseline BMI and positively with clinical global improvement and the length of olanzapine treatment, but it did not correlate with the daily dose of olanzapine, concomitant antipsychotics, sex, age, or smoking. Four genetic variants, the $102 \mathrm{~T}$ allele of HTR $2 A$, the $825 \mathrm{~T}$ allele of GNB3, the 23Cys allele of HTR2C, and the 64Arg/Arg genotype of $A D R B 3$, were significantly associated with olanzapineinduced weight gain. Stepwise regression analysis revealed that the baseline BMI predicted $12.5 \%$ of the weight gain, and the 2 latter genetic factors added $6.8 \%$. The patients with double and triple genetic risk factors showed 5.1 and $8.8 \%$ BMI increases, respectively, during olanzapine treatment, whereas the patients with a single or no risk factor showed approximately a $1 \%$ BMI increase [144].

Genetic predisposition to CLZ -induced weight gain has also been suggested. Ten genetic polymorphisms across 9 candidate genes, including the serotonin $2 \mathrm{C}, 2 \mathrm{~A}$, and $1 \mathrm{~A}$ receptor genes $(H T R 2 C / 2 A / 1 A)$; the histamine $\mathrm{H}_{1}$ and $\mathrm{H}_{2}$ receptor genes (H1R/H2R); the cytochrome P450 1A2 gene (CYPIA2); the beta3 and alpha,alpha-adrenergic receptor genes (ADRB3/ADRAIA); and tumor necrosis factor alpha (TNF-alpha) have been studied. Trends were observed for ADRB3, ADRAIA, TNF-alpha, and HTR2C [145].

5-HT2C and 5-HT2A antagonisms are hypothesized to play a role in the metabolic adverse effects induced by olanzapine and CLZ. Associations between polymorphisms in 5-HT2C and 5-HT2A receptor coding genes, $H T R 2 C$, and $H T R 2 A$, with antipsychoticinduced weight gain have been reported. Olanzapine-treated patients with HTR2C haplotype C (-759C, -697C, and 23Ser) had higher BMI and $\mathrm{C}$ peptide levels compared with patients with haplotype B (-759T, -697C, and 23Cys). The frequency of patients homozygous for the HTR2C haplotype A (-759C, -697G, and 23Cys) was significantly higher among CLZ -treated patients with obesity $(\mathrm{BMI}>30 \mathrm{~kg} / \mathrm{m})$ compared with nonobese patients. Patients carrying the HTR2A haplotype 2 (-1438A, 102T, and 452His) had significantly higher $\mathrm{C}$ peptide levels compared with haplotype 3 (-1438A, 102T, and 452Tyr) carriers in the olanzapine group and in the overall study population [146]. An association between HTR2C polymorphisms and the occurrence of the metabolic syndrome in patients using antipsychotics has also been reported. Pri- mary determinants were polymorphisms in the promoter region of the HTR2C gene (HTR2C:c.1-142948[GT], rs3813929 [-759 $\mathrm{C} / \mathrm{T}]$, and rs518147 [-697 G/C]) and an intragenic polymorphism (rs1414334:C>G). The variants of HTR2C:c.1-142948(GT) $\mathrm{n}$ and rs1414334 were not significantly associated with the metabolic syndrome in the replication sample but did show significance in the pooled analysis. The variant rs $1414334 \mathrm{C}$ allele was specifically associated with the metabolic syndrome in patients using CLZ or risperidone. The increased risk for the metabolic syndrome is particularly strong in carriers of the rs $1414334 \mathrm{C}$ allele using CLZ or risperidone [147].

The LEPR Q223R polymorphism (rs1 137101) and the LEP promoter 2548G/A polymorphism (rs7799039) were postulated as candidate genes to be associated with obesity in patients using atypical antipsychotic drugs. In females, the LEPR 223QR and LEPR 223RR genotypes were associated with a lower risk of obesity. In males, this association was not found. In females, the average body weight was $13.6 \mathrm{~kg}$ more in the LEPR 223QQ group compared with the LEPR 223RR group. No significant association was found between the LEP promoter 2548G/A polymorphism and obesity [148].

Sequence variations in the glutamate transporter gene SLC1A1 (A/C/G haplotype at rs2228622-rs3780413-rs3780412) have been associated with susceptibility to atypical antipsychotic-induced obsessive-compulsive symptoms [149].

Several polymorphisms previously associated with the efficacy of the novel antipsychotic iloperidone could be used together to predict clinical response and provide practical information for individualized treatment. A recent study using 6 genetic markers of iloperidone response as measured by change in the Positive and Negative Syndrome Scale-Total (PANSS-T) score demonstrated that the 6-marker genotype combinations defined 4 groups of patients with distinct probabilities of response. Over $75 \%$ of iloperidone-treated patients in the group with the optimal genotype combinations showed a $20 \%$ or greater improvement, compared with $37 \%$ for patients with other genotypes [150].

Genome-wide expression profiling microarrays to study effects of typical antipsychotics and atypical antipsychotics in the postmortem liver of SCZ patients revealed that typical antipsychotics affected genes associated with nuclear protein, stress responses, and phosphorylation, whereas atypical antipsychotics affected genes associated with Golgi/endoplasmic reticulum and cytoplasm transport. Comparison between typical antipsychotics and atypical antipsychotics further identified genes associated with lipid metabolism and mitochondrial function. Analyses on individual antipsychotics identified a set of genes (151 transcripts) that are differentially regulated by 4 antipsychotics, particularly by phenothiazines, in the liver of SCZ patients [151].

Growing genetic evidence has implicated a role for NRG-1 in SCZ pathogenesis as well as alterations in SNAP receptor (SNARE) proteins at both gene and protein levels in postmortem investigations. CLZ has been shown to increase both NRG-1 levels and synaptic markers in rodents. CLZ has the ability to upregulate $N R G-1$ (+3.58-fold change) and VAMP-1 (+1.92) while SNAP-25 remaines unchanged [152]. 


\section{Drug-Related Proteomics}

An increasing number of experiments have found anomalies in mitochondria in the brains of psychotics, which suggests that mitochondrial dysfunction or abnormal cerebral energy metabolism might play an important role in the pathophysiology of SCZ. Differential mitochondrial protein expressions were assessed using two-dimensional (2D) gel electrophoresis for three groups with chlorpromazine (CPZ), CLZ, quetiapine (QTP), and a control group. A total of 14 proteins, of which 6 belong to the respiratory electron transport chain (ETC) of oxidative phosphorylation (OXPHOS), showed significant changes in quantity including NADH dehydrogenase (ubiquinone) 1 alpha subcomplex 10 (Ndufal0), NADH dehydrogenase (ubiquinone) flavoprotein 2 (Ndufv2), NADH dehydrogenase (ubiquinone) Fe-S protein 3 (Ndufs3), F1-ATPase beta subunit (Atp5b), ATPase, $\mathrm{H}^{+}$transporting, lysosomal, beta $56 / 58 \mathrm{kDa}$, isoform 2 (Atp6vlb2) and ATPase, $\mathrm{H}^{+}$transporting, $\mathrm{Vl}$ subunit A, isoform l (Atp6vlal). These data show proteomic changes induced by neuroleptics in rodents [153]. Label-free liquid chromatography tandem mass spectrometry (LC-MSE) was used to identify differentially expressed proteins in rat frontal cortex following subchronic treatment with haloperidol or olanzapine. LC-MSE profiling identified 531 and 741 annotated proteins in fractions I (cytoplasmic-) and II (membrane enriched-) in the 2 drug treatments. Fifty-nine of these proteins were altered significantly by haloperidol treatment, 74 by olanzapine, and 21 were common to both treatments. Pathway analysis revealed that both drugs altered similar classes of proteins associated with cellular assembly/organization, nervous system development/function (particularly presynaptic function), and neurological disorders, which indicate a common mechanism of action. The top affected canonical signaling pathways differed between the two treatments. The haloperidol data set showed a stronger association with Huntington's disease signaling, while olanzapine treatment showed stronger effects on glycolysis/gluconeogenesis [154].

Selective serotonin reuptake inhibitor (SSRI) and antipsychotic coadministration is a widely used strategy to treat both psychotic depression and depressive symptoms in SCZ. Coadministration of SSRIs and antipsychotics may result in molecular changes different from their individual effects. Studies have been carried out on the acute effects of two SSRIs, citalopram, and escitalopram, alone or in combination with haloperidol, on the expression of Homerla together with its splice variant ania-3, and p11, 2 genes linked respectively to dopaminergic and serotonergic neurotransmission and involved in synaptic plasticity. Homerla and ania-3 were induced in the striatum by haloperidol, alone and in combination with SSRIs, but not by SSRIs alone. Haloperidol+citalopram co-administration induced a stronger Homerla expression than haloperidol alone in the ventrolateral caudate-putamen. Homerla was significantly downregulated in the parietal cortex by all treatments. These results show that haloperidol + citalopram combination exerts synergistic effects on Homer expression, suggesting that citalopram may influence the impact of haloperidol on dopaminergic neurotransmission. Homerla and ania-3 are strongly induced in striatum by haloperidol, while they are not influenced by citalopram or escitalopram in this region. In the cortex the two transcripts are modulated by both haloperidol and SSRIs, suggesting a possible role of both dopamine and serotonin in their cortical regulation [155].

\section{Conclusions}

SCZ is a multifactorial, polygenic/complex disorder in which more than 100 different genes distributed across the human genome might be involved. Polymorphic variants in many SCZ-related candidate genes may give rise to proteomic dysfunctions associated with SCZ pathogenesis (e.g., neurodevelopmental defects, neurotransmitter dysregulation). As an example, altered expression of DISCl and/or its molecular partners (nuclear distribution element-like [NUDEL], fasciculation and elongation protein zeta-i [FEZ1], and lissencephaly 1 [LIS1]) may underlie its pathogenic role in SCZ and partially explain its genetic association [156,157]. Epigenetic factors may also play a major role in SCZ pathogenesis and response to therapeutic intervention. Both CYP-related genes and genes associated with SCZ and/or with drug mechanism of action are responsible for efficacy and safety issues in the pharmacotherapy of SCZ. An effective, personalized treatment of SCZ patients would require a pharmacogenomic approach in order to optimize the use of neuroleptics and other psychotropic drugs. Excluding exogenous factors, the therapeutic response to these compounds mainly depends upon genetic and epigenetic factors, including CYP variants and SCZ-related genomic profiles. From a practical point of view, pharmacoeconomic studies have to validate the utility of genetic testing in CNS disorders to optimize therapeutics with conventional drugs [158]. In terms of drug development, novel pharmacogenomic approaches have to be incorporated into current strategies in drug primary screening, preclinical studies (transfected cells, transgenic animals, disease-specific biochips), and clinical trials.

\section{Acknowledgments}

We thank our colleagues at EuroEspes Biomedical Research Center and Ebiotec for their technical assistance. Most studies on pharmacogenomics of CNS disorders in our institution have been supported by IABRA (International Agency for Brain Research and Aging) and the EuroEspes Foundation.

\section{Conflict of Interest}

No potential conflict of interest relevant to this article is declared.

\section{References}

1. Aparasu RR, Jano E, Bhatara V. Concomitant antipsychotic prescribing in US outpatient settings. Res Social Adm Pharm 2009;5:234-241.

2. Sankaranarayanan J, Puumala SE. Antipsychotic use at adult ambulatory care visits by patients with mental health disorders in the United States, 1996-2003: National estimates and associated factors. Clin Ther 2007;29:723-741.

3. Cacabelos R. Pharmacogenomic biomarkers in neuropsychiatry: The path to personalized medicine in mental disorders. In: Ritsner MS, editor. The handbook of neuropsychiatric biomarkers, endophenotypes and genes, Vol. 4. Springer, 2009;3-63.

4. Cacabelos R. Pharmacogenomics and therapeutic strategies for dementia. Expert Rev Mol Diag 2009;9:567-611.

5. Cacabelos R. Pharmacogenomics in Alzheimer's disease. Meth Mol Biol 2008;448:213-357.

6. Cacabelos R. Molecular genetics of Alzheimer's disease and aging. Meth Find Exper Clin Pharmacol 2005;27(Suppl A):1-573. 
7. Cacabelos R. Pharmacogenomics for the treatment of dementia. Ann Med 2002;34:357379.

8. Cacabelos R. The application of functional genomics to Alzheimer's disease. Pharmacogenomics 2003;4:597-621.

9. Cacabelos R. Pharmacogenomics and therapeutic prospects in Alzheimer's disease. Exp Opin Pharmacother 2005;6:1967-1987.

10. Cacabelos R. Pharmacogenomics, nutrigenomics and therapeutic optimization in Alzheimer's disease. Aging Health 2005;1:303-348.

11. Cacabelos R, Takeda M. Pharmacogenomics, nutrigenomics and future therapeutics in Alzheimer's disease. Drugs Future 2006;31(Suppl B):5-146.

12. Roses AD. Pharmacogenetics and drug development: The path to safer and more effective drugs. Nat Rev Genet 2004;5:645-656.

13. Sharp AJ, Cheng Z, Eichler EE. Structural variation of human genome. Annu Rev Genomics Hum Genet 2006; 7:407-442.

14. Crawford DC, Akey DT, Nickerson DA. The patterns of natural variation in human genes. Annu Rev Genomics Hum Genet 2005;6:287-312.

15. National Center for Biotechnology Information. Available from: http://www.ncbi.nlm.nih.gov/OMIM [Assessed 5 March 2010].

16. Alzheimer Research Forum. Available from: http://www.alzgene.org [Assessed 5 March 2010].

17. Howes OD, Kapur S. The dopamine hypothesis of schizophrenia: Version III-the final common pathway. Schizophr Bull 2009;35:549-562.

18. Bennett M. Positive and negative symptoms in schizophrenia: The NMDA receptor hypofunction hypothesis, neuregulin/ErbB4 and synapse regression. Aust N Z J Psychiatry 2009;43:711-721.

19. Fatemi SH, Folsom TD. The neurodevelopmental hypothesis of schizophrenia, revisited. Schizophr Bull 2009;35:528-548.

20. Häfner H. Gender differences in schizophrenia. Psychoneuroendocrinology 2003;28(Suppl 2):17-54.

21. Chen LS, Rice TK, Thompson PA, et al. Familial aggregation of clinical and neurocognitive features in sibling pairs with and without schizophrenia. Schizophr Res 2009;111:159-166.

22. Lichtenstein P, Yip BH, Björk C, et al. Common genetic determinants of schizophrenia and bipolar disorder in Swedish families: A population-based study. Lancet 2009;373:234-239.

23. Doi N, Hoshi Y, Itokawa M, et al. Persistence criteria for susceptibility genes for schizophrenia: A discussion from an evolutionary viewpoint. PLoS One 2009;4:e7799. doi: 10.1371/journal.pone.0007799.

24. Knight HM, Pickard BS, Maclean A, et al. A cytogenetic abnormality and rare coding variants identify $\mathrm{ABCA} 13$ as a candidate gene in schizophrenia, bipolar disorder, and depression. Am J Hum Genet 2009;85:833-846.

25. Ingason A, Giegling I, Cichon S, et al. A large replication study and meta-analysis in European samples provides further support for association of AHIl markers with schizophrenia. Hum Mol Genet 2010;19:1379-1386

26. Ikeda M, Tomita Y, Mouri A, et al. Identification of novel candidate genes for treatment response to risperidone and susceptibility for schizophrenia: Integrated analysis among pharmacogenomics, mouse expression, and genetic case-control association approaches. Biol Psychiatry 2010;67:263-269.

27. Zhang F, Xu Y, Liu P, et al. Association analyses of the interaction between the ADSS and ATM genes with schizophrenia in a Chinese population. BMC Med Genet 2008;9:119.

28. Vik-Mo AO, Fernø J, Skrede S, et al. Psychotropic drugs up-regulate the expression of cholesterol transport proteins including ApoE in cultured human CNS- and liver cells. BMC Pharmacol 2009;9:10

29. Chen X, Sun C, Chen Q, et al. Apoptotic engulfment pathway and schizophrenia. PLoS One 2009;4:e6875. doi:10.1371/journal.pone.0006875.

30. Kawashima K, Ikeda M, Kishi T, et al. BDNF is not associated with schizophrenia: Data from a Japanese population study and meta-analysis. Schizophr Res 2009;112:72-79.

31. Chang HA, Lu RB, Shy MJ, et al. Brain-derived neurotrophic factor Val66Met polymorphism: Association with psychopathological symptoms of schizophrenia? J Neuropsychiatry Clin Neurosci 2009;21:30-37.

32. Lencz T, Lipsky RH, DeRosse P, et al. Molecular differentiation of schizoaffective disorder from schizophrenia using BDNF haplotypes. Br J Psychiatry 2009;194:313-318.

33. Wong J, Webster MJ, Cassano H, et al. Changes in alternative brain-derived neurotrophic factor transcript expression in the developing human prefrontal cortex. Eur J Neurosci 2009;29:1311-1322.

34. Dunham JS, Deakin JF, Miyajima F, et al. Expression of hippocampal brain-derived neurotrophic factor and its receptors in Stanley consortium brains. J Psychiatr Res 2009;43:1175-1184

35. Park SW, Lee JG, Kong BG, et al. Genetic association of BDNF val66met and GSK-3beta-50T/C polymorphisms with tardive dyskinesia. Psychiatry Clin Neurosci 2009;63:433-439.

36. Cheli VT, Daniels RW, Godoy R, et al. Genetic modifiers of abnormal organelle biogenesis in a Drosophila model of BLOC-1 deficiency. Human Mol Genet 2010;19:861-872.

37. Green EK, Grozeva D, Jones I, et al. The bipolar disorder risk allele at CACNAIC also confers risk of recurrent major depression and of schizophrenia. Mol Psychiatry 2009. doi:10.1038/mp.2009.49.

38. The Bipolar Disorder Genome Study (BiGS) Consortium, McMahon FJ, Akula N, et al.
Meta-analysis of genome-wide association data identifies a risk locus for major mood disorders on 3p21.1. Nat Genet 2010;42:128-131.

39. Ishiguro H, Horiuchi $Y$, Ishikawa $M$, et al. Brain cannabinoid $C B 2$ receptor in schizophrenia. Biol Psychiatry 2009;67:974-982.

40. Minato T, Tochigi M, Kato N, et al. Association study between the cholecystokinin A receptor gene and schizophrenia in the Japanese population. Psychiatr Genet 2007;17:117-119.

41. Sinkus ML, Lee MJ, Gault J, et al. A 2-base pair deletion polymorphism in the partial duplication of the alpha7 nicotinic acetylcholine gene (CHRFAM7A) on chromosome 15q14 is associated with schizophrenia. Brain Res 2009;1291:1-11.

42. Stephens SH, Logel J, Barton A, et al. Association of the 5'-upstream regulatory region of the alpha7 nicotinic acetylcholine receptor subunit gene (CHRNA7) with schizophrenia. Schizophr Res 2009; 109:102-112.

43. Zweier C, de Jong EK, Zweier M, et al. CNTNAP2 and NRXN1 are mutated in autosomal-recessive Pitt-Hopkins-like mental retardation and determine the level of a common synaptic protein in drosophila. Am J Hum Genet 2009;85:655-666.

44. Rutherford K, Daggett V. A hotspot of inactivation: The A22S and V108M polymorphisms individually destabilize the active site structure of catechol O-methyltransferase. Biochemistry 2009;48:6450-6460.

45. Wang Y, Hu Y, Fang Y, et al. Evidence of epistasis between the catechol-O-methyltransferase and aldehyde dehydrogenase 3Bl genes in paranoid schizophrenia. Biol Psychiatry 2009;65:1048-1054.

46. Ma J, Sun J, Zhang H, et al. Evidence for transmission disequilibrium at the DAOA gene locus in a schizophrenia family sample. Neurosci Lett 2009;462:105-108.

47. Ohi K, Hashimoto R, Yasuda Y, et al. Association study of the G72 gene with schizophrenia in a Japanese population: A multicenter study. Schizophr Res 2009;109:80-85.

48. Detera-Wadleigh SD, McMahon FJ. G72/G30 in schizophrenia and bipolar disorder: Review and meta-analysis. Biol Psychiatry 2006;60:106-114.

49. Gomez L, Wigg K, Feng Y, et al. G72/G30 (DAOA) and juvenile-onset mood disorders. Am J Med Genet B Neuropsychiatr Genet 2009;150:1007-1012.

50. Matsuzaki S, Tohyama M. Molecular mechanism of schizophrenia with reference to disrupted-in-schizophrenia 1 (DISC1). Neurochem Int 2007;51:165-172.

51. Millar JK, Mackie S, Clapcote SJ, et al. Disrupted in schizophrenia 1 and phosphodiesterase 4B: Towards an understanding of psychiatric illness. J Physiol 2007;584(Pt 2):401-405.

52. Bradshaw NJ, Ogawa F, Antolin-Fontes B, et al. DISC1, PDE4B, and NDEl at the centrosome and synapse. Biochem Biophys Res Commun 2008;377:1091-1096.

53. Tomppo L, Hennah W, Lahermo P, et al. Association between genes of disrupted in schizophrenia 1 (DISC1) interactors and schizophrenia supports the role of the DISC1 pathway in the etiology of major mental illnesses. Biol Psychiatry 2009;65: 1055-1062.

54. Kähler AK, Otnaess MK, Wirgenes KV, et al. Association study of PDE4B gene variants in Scandinavian schizophrenia and bipolar disorder multicenter case-control samples. Am J Med Genet B Neuropsychiatr Genet 2010;153B:86-96.

55. Zhang C, Fang Y, Xie B, et al. DNA methyltransferase 3B gene increases risk of early onset schizophrenia. Neurosci Lett 2009;462:308-311.

56. Zhubi A, Veldic M, Puri NV, et al. An upregulation of DNA-methyltransferase 1 and 3a expressed in telencephalic GABAergic neurons of schizophrenia patients is also detected in peripheral blood lymphocytes. Schizophr Res 2009;111:115-122.

57. Reuter M, Weber B, Fiebach CJ, et al. The biological basis of anger: Associations with the gene coding for DARPP-32 (PPPIR1B) and with amygdala volume. Behav Brain Res 2009;202:179-183.

58. Srivastava V, Deshpande SN, Thelma BK. Dopaminergic pathway gene polymorphisms and genetic susceptibility to schizophrenia among north Indians. Neuropsychobiology 2009;61:64-70.

59. Prata DP, Mechelli A, Fu CH, et al. Epistasis between the DAT 3' UTR VNTR and the COMT Val158Met SNP on cortical function in healthy subjects and patients with schizophrenia. Proc Natl Acad Sci U S A 2009;106:13600-13605.

60. Gupta M, Chauhan C, Bhatnagar P, et al. Genetic susceptibility to schizophrenia: Role of dopaminergic pathway gene polymorphisms. Pharmacogenomics 2009;10:277-291.

61. Hattori E, Nakajima M, Yamada K, et al. Variable number of tandem repeat polymorphisms of DRD4: Re-evaluation of selection hypothesis and analysis of association with schizophrenia. Eur J Hum Genet 2009;17:793-801.

62. Zai CC, Tiwari AK, De Luca V, et al. Genetic study of BDNF, DRD3, and their interaction in tardive dyskinesia. Eur Neuropsychopharmacol 2009;19:317-328.

63. Maher BS, Reimers MA, Riley BP, et al. Allelic heterogeneity in genetic association meta-analysis: An application to DTNBP1 and schizophrenia. Hum Hered 2009;69: $71-79$.

64. Dwyer S, Carroll L, Mantripragada KK, et al. Mutation screening of the DTNBPI exonic sequence in 669 schizophrenics and 710 controls using high-resolution melting analysis. Am J Med Genet B Neuropsychiatr Genet 2009; 1538:766-774.

65. Ryder PV, Faundez V. Schizophrenia: The "BLOC" may be in the endosomes. Sci Signal 2009;2:pe66.

66. Donohoe G, Frodl T, Morris D, et al. Reduced occipital and prefrontal brain volumes in dysbindin-associated schizophrenia. Neuropsychopharmacology 2010;35:368-373.

67. Pae CU, Mandelli L, De Ronchi D, et al. Dysbindin gene (DTNBP1) and schizophrenia in Korean population. Eur Arch Psychiatry Clin Neurosci 2009;259:137-142. 
68. Gaysina D, Cohen-Woods S, Chow PC, et al. Association of the dystrobrevin binding protein 1 gene (DTNBPI) in a bipolar case-control study (BACCS). Am J Med Genet B Neuropsychiatr Genet 2009;150:836-844.

69. Wong J, Weickert CS. Transcriptional interaction of an estrogen receptor splice variant and ErbB4 suggests convergence in gene susceptibility pathways in schizophrenia. J Biol Chem 2009:284:18824-18832.

70. Li D, Feng G, He L. Case-control study of association between the functional candidate gene ERBB3 and schizophrenia in Caucasian population. World J Biol Psychiatry 2009;10(4 Pt 2):595-598.

71. Kulkarni J. Oestrogen-a new treatment approach for schizophrenia? Med J Aust 2009;190(4 Suppl):S37-S38,

72. McNamara RK, Jandacek R, Rider T, et al. Abnormalities in the fatty acid composition of the postmortem orbitofrontal cortex of schizophrenic patients: Gender differences and partial normalization with antipsychotic medications. Schizophr Res 2007;91:37-50.

73. Liu Y, Jandacek R, Rider T, et al. Elevated delta-6 desaturase (FADS2) expression in the postmortem prefrontal cortex of schizophrenic patients: Relationship with fatty acid composition. Schizophr Res 2009;109:113-120.

74. Hattori K, Fukuzako H, Hashiguchi T, et al. Decreased expression of Fyn protein and disbalanced alternative splicing patterns in platelets from patients with schizophrenia. Psychiatry Res 2009;168:119-128.

75. Szczepankiewicz A, Rybakowski JK, Skibinska M, et al. FYN kinase gene: Another glutamatergic gene associated with bipolar disorder? Neuropsychobiology 2009;59: $178-183$.

76. Mellios N, Huang HS, Baker SP, et al. Molecular determinants of dysregulated GABAergic gene expression in the prefrontal cortex of subjects with schizophrenia. Biol Psychiatry 2009;65:1006-1014

77. Butticaz C, Werge T, Beckmann JS, et al. Mutation screening of the glutamate cysteine ligase modifier (GCLM) gene in patients with schizophrenia. Psychiatr Genet 2009;19: 201-208.

78. Segnitz N, Schmitt A, Gebicke-Härter PJ, et al. Differential expression of glutamate transporter genes after chronic oral treatment with aripiprazole in rats. Neurochem Int 2009;55: 619-628.

79. Baruch K, Silberberg G, Aviv A, et al. Association between golli-MBP and schizophrenia in the Jewish Ashkenazi population: Are regulatory regions involved? Int J Neuropsychopharmacol 2009; 12:885-894.

80. Sun S, Wei J, Li H, et al. A family-based study of the IL3RA gene on susceptibility to schizophrenia in a Chinese Han population. Brain Res 2009;1268:13-16.

81. Huffaker SJ, Chen J, Nicodemus KK, et al. A primate-specific, brain isoform of KCNH2 affects cortical physiology, cognition, neuronal repolarization and risk of schizophrenia. Nat Med 2009:15:509-518.

82. Miller CL, Murakami P, Ruczinski I, et al. Two complex genotypes relevant to the kynurenine pathway and melanotropin function show association with schizophrenia and bipolar disorder. Schizophr Res 2009;113:259-267.

83. Djurovic S, Le Hellard S, Kähler AK, et al. Association of MCTP2 gene variants with schizophrenia in three independent samples of Scandinavian origin (SCOPE). Psychiatry Res 2009; 168:256-258

84. International Schizophrenia Consortium, et al. Rare chromosomal deletions and duplications increase risk of schizophrenia. Nature 2008;455:237-241.

85. Stefansson H, Ophoff RA, Steinberg S, et al. Common variants conferring risk of schizophrenia. Nature 2009;460:744-747.

86. Feng LG, Song ZW, Xin F, et al. Association of plasma homocysteine and methylenetetrahydrofolate reductase C677T gene variant with schizophrenia: A Chinese Han population-based case-control study. Psychiatry Res 2009;168:205-208

87. Alaerts M, Ceulemans S, Forero D, et al. Support for NRG1 as a susceptibility factor for schizophrenia in a northern Swedish isolated population. Arch Gen Psychiatry 2009;66:828-837.

88. Li D, Collier DA, He L. Meta-analysis shows strong positive association of the neuregulin 1 (NRG1) gene with schizophrenia. Hum Mol Genet 2006;15:1995-2002.

89. Gong YG, Wu CN, Xing QH, et al. A two-method meta-analysis of Neuregulin 1(NRG1) association and heterogeneity in schizophrenia. Schizophr Res 2009;111:109-114.

90. Zhang HX, Li WQ, Zhang Y, et al. Association analysis of neuregulin 1 gene polymorphism with schizophrenia in Chinese Han population. Zhonghua Yi Xue Yi Chuan Xue Za Zhi 2009;26:16-20.

91. Chen PL, Avramopoulos D, Lasseter VK, et al. Fine mapping on chromosome 10q22-q23 implicates Neuregulin 3 in schizophrenia. Am J Hum Genet 2009;84:21-34.

92. Stefansson H, Rujescu D, Cichon S, et al. Large recurrent microdeletions associated with schizophrenia. Nature 2008; 455:232-236

93. Ruano D, Aulchenko YS, Macedo A, et al. Association of of the gene encoding neurogranin with schizophrenia in males. J Psychiat Res 2008;42:125-133.

94. Goes FS, Willour VL, Zandi PP, et al. Sex-specific association of the reelin gene with bipolar disorder. Am J Med Genet B Neuropsychiatr Genet 2009;153B:549-553.

95. Wedenoja J, Tuulio-Henriksson A, Suvisaari J, et al. Replication of association between working memory and reelin, a potential modifier gene in schizophrenia. Biol Psychiatry 2009;67:983-991.
96. Lintas C, Persico AM. Neocortical RELN promoter methylation increases significantly after puberty. Neuroreport 2010;21:114-118.

97. Campo CG, Sinagra M, Verrier D, et al. Reelin secreted by GABAergic neurons regulates glutamate receptor homeostasis. PLoS One 2009;4:e5505.

98. Ammassari-Teule M, Sgobio C, Biamonte F, et al. Reelin haploinsufficiency reduces the density of PV+ neurons in circumscribed regions of the striatum and selectively alters striatal-based behaviors. Psychopharmacology (Berl) 2009;204:511-521.

99. Tueting P, Doueiri MS, Guidotti A, et al. Reelin down-regulation in mice and psychosis endophenotypes. Neurosci Biobehav Rev 2006;30:1065-1077.

100. Noh JS, Sharma RP, Veldic M, et al. DNA methyltransferase 1 regulates reelin mRNA expression in mouse primary cortical cultures. Proc Natl Acad Sci U S A 2005;102 1749-1754.

101. Vijayan NN, Iwayama Y, Koshy LV, et al. Evidence of association of serotonin transporter gene polymorphisms with schizophrenia in a South Indian population. J Hum Genet 2009;54:538-542.

102. Koga M, Ishiguro H, Yazaki S, et al. Involvement of SMARCA2/BRM in the SWI/SNF chromatin-remodeling complex in schizophrenia. Hum Mol Genet 2009; 18:2483-2494.

103. Fellerhoff $B$, Wank R. Transporter associated with antigen processing and the chaperone tapasin: Are non-classical HLA genes keys to the pathogenesis of schizophrenia? Med Hypotheses 2009;72:535-538.

104. Ohi K, Hashimoto R, Yasuda Y, et al. TATA box-binding protein gene is associated with risk for schizophrenia, age at onset and prefrontal function. Genes Brain Behav 2009;8: $473-480$.

105. Locke M, Tinsley CL, Benson MA, et al. TRIM32 is an E3 ubiquitin ligase for dysbindin. Human Mol Genet. 2009;18:2344-2358.

106. Grover D, Verma R, Goes FS, et al. Family-based association of YWHAH in psychotic bipolar disorder. Am J Med Genet B Neuropsychiatr Genet 2009;150:977-983.

107. Wimalasena K. Vesicular monoamine transporters: Structure-function, pharmacology, and medicinal chemistry. Med Res Rev 2010. doi: 10.1002/med.20187.

108. Lohoff FW, Weller AE, Bloch PJ, et al. Association between polymorphisms in the vesicular monoamine transporter 1 gene (VMATl/SLC18Al) on chromosome 8p and schizophrenia. Neuropsychobiology 2008;57:55-60.

109. Lohoff FW, Dahl JP, Ferraro TN, et al. Variations in the vesicular monoamine transporter 1 gene (VMAT1/SLC18A1) are associated with bipolar i disorder. Neuropsychopharmacology 2006;31:2739-2747.

110. Richards M, Iijima Y, Kondo H, et al. Association study of the vesicular monoamine transporter 1 (VMATl) gene with schizophrenia in a Japanese population. Behav Brain Funct 2006;2:39.

111. Derakhshandeh S, Saadat I, Farrashbandi H, et al. Association between genetic polymorphism of XRCC1 Arg194Trp and risk of schizophrenia. Psychiatry Res 2009;169:186.

112. Riley B, Thiselton D, Maher BS, et al. Replication of association between schizophrenia and ZNF804A in the Irish case-control study of schizophrenia sample. Mol Psychiatry 2010;15:29-37.

113. Esslinger C, Walter $\mathrm{H}$, Kirsch $\mathrm{P}$, et al. Neural mechanisms of a genome-wide supported psychosis variant. Science 2009;324:605.

114. Malhotra AK, Lencz T, Correll CU, Kane JM. Genomics and the future of pharmacotherapy in psychiatry. Int Rev Psychiatry 2007; 19:523-530.

115. Nnadi CU, Malhorta AK. Individualizing antipsychotic drug therapy in schizophrenia: The promise of pharmacogenetics. Curr Psychiatry Rep 2007;9:313-318.

116. Foster A, Miller D, Buckley PF. Pharmacogenetics and schizophrenia. Psychiatr Clin North Am 2007;30:417-435.

117. Arranz MJ, de Leon J. Pharmacogenetics and pharmacogenomics of schizophrenia: A review of last decade of research. Mol Psychiatry 2007;12:707-747.

118. Verrils NM. Clinical proteomics: Present and future prospects. Clin Biochem Rev 2006;27:99-116.

119. Mizutani T. PM frequencies of major CYPs in Asians and Caucasians. Drug Metab Rev 2003;35:99-106

120. Xie HG, Prasad HG, Kim RB, et al. CYP2C9 allelic variants: Ethnic ditribution and functional significance. Adv Drug Deliv Rev 2002;54:1257-1270.

121. Isaza CA, Henao J, López AM, Cacabelos R. Isolation, sequence and genotyping of the drug metabolizer CYP2D6 gene in the Colombian population. Meth Find Exp Clin Pharmacol 2000;22:695-705.

122. Ozawa S, Soyama A, Saeki M, et al. Ethnic differences in genetic polymorphisms of CYP2D6, CYP2C19, CYP3As and MDR1/ABCB 1. Drug Metab Pharmacokin 2004;19:83-95.

123. Cacabelos R. Pharmacogenomic protocols in CNS disorders and dementia. Neurodegenerative Dis 2010;7:167-169. doi: 10.1159/000289230.

124. Scordo MG, Spina E. Cytochrome P450 polymorphisms and response to antipsychotic therapy. Pharmacogenomics 2002;3:201-218.

125. Ingelman-Sundberg M, Sim SC, Gomez A, et al. Influence of cytochrome P450 polymorphisms on drug therapies: Pharmacogenetic, pharmacoepigenetic and clinical aspects. Pharmacol Ther 2007;116:496-526.

126. Kobylecki CJ, Jakobsen KD, Hansen T, et al. CYP2D6 genotype predicts antipsychotic side effects in schizophrenia inpatients: A retrospective matched case-control study. Neuropsychobiology 2009;59:222-226. 
127. Yagihashi T, Mizuno M, Chino B, et al. Effects of the CYP2D6*10 alleles and co-medication with CYP2D6-dependent drugs on risperidone metabolism in patients with schizophrenia. Hum Psychopharmacol 2009;24:301-308.

128. Kang RH, Jung SM, Kim KA, et al. Effects of CYP2D6 and CYP3A5 genotypes on the plasma concentrations of risperidone and 9-hydroxyrisperidone in Korean schizophrenic patients. $J$ Clin Psychopharmacol 2009;29:272-277.

129. Buchanan RW, Freedman R, Javitt DC, et al. Recent advances in the development of novel pharmacological agents for the treatment of cognitive impairments in schizophrenia. Schizophr Bull 2007;33:1120-1130.

130. Tamminga CA. The neurobiology of cognition in schizophrenia. J Clin Psychiatry 2006;67:36-42.

131. Malhotra AK, Murphy GM Jr, Kennedy JL. Pharmacogenetics of psychotropic drug response. Am J Psychiatry 2004;161:780-796.

132. de Leon J. The future (or lack of future) of personalized prescription in psychiatry. Pharmacol Res 2009;59:81-89.

133. Need AC, Keefe RS, Ge D, et al. Pharmacogenetics of antipsychotic response in the CATIE trial: A candidate gene analysis. Eur J Hum Genet 2009;17:946-957.

134. Iwahashi K, Murayama O, Aoki J, et al. Influence of serotonin (5-HT) $2 \mathrm{~A}$-receptor and transporter (5HTT) gene polymorphism upon the effect of olanzapine. Nihon Shinkei Seishin Yakurigaku Zasshi 2009;29:141-144.

135. Chen SF, Shen YC, Chen CH. Effects of the DRD3 Ser9Gly polymorphism on aripiprazole efficacy in schizophrenic patients as modified by clinical factors. Prog Neuropsychopharmacol Biol Psychiatry 2009;33:470-474.

136. Chen SF, Shen YC, Chen CH. HTR2A A-1438G/T102C polymorphisms predict negative symptoms performance upon aripiprazole treatment in schizophrenic patients. Psychopharmacology (Berl) 2009;205:285-292.

137. Park SW, Lee JG, Ha EK, et al. Differential effects of aripiprazole and haloperidol on BDNF-mediated signal changes in SH-SY5Y cells. Eur Neuropsychopharmacol 2009;19: 356-362.

138. Zuo L, Luo X, Krystal JH, et al. The efficacies of clozapine and haloperidol in refractory schizophrenia are related to DTNBP1 variation. Pharmacogenet Genomics 2009;19:437-446.

139. Fatemi SH, Reutiman TJ, Folsom TD. Chronic psychotropic drug treatment causes differential expression of Reelin signaling system in frontal cortex of rats. Schizophr Res 2009;111:138-152.

140. Guidotti A, Dong E, Kundakovic M, et al. Characterization of the action of antipsychotic subtypes on valproate-induced chromatin remodeling. Trends Pharmacol Sci 2009;30:55-60.

141. Cashman JR, Zhang J, Nelson MR, et al. Analysis of flavin-containing monooxygenase 3 genotype data in populations administered the anti-schizophrenia agent olanzapine. Drug Metab Lett 2008;2:100-114

142. Gupta M, Bhatnagar P, Grover S, et al. Association studies of catechol-O-methyltransferase (COMT) gene with schizophrenia and response to antipsychotic treatment. Pharmacogenomics 2009; 10:385-397.

143. Herken H, Erdal M, Aydin N, et al. The association of olanzapine-induced weight gain with peroxisome proliferator-activated receptor-gamma2 Prol2Ala polymorphism in patients with schizophrenia. DNA Cell Biol 2009;28:515-519.

144. Ujike H, Nomura A, Morita Y, et al. Multiple genetic factors in olanzapine-induced weight gain in schizophrenia patients: A cohort study. J Clin Psychiatry 2008;69:1416-1422.
145. Basile VS, Masellis M, McIntyre RS, et al. Genetic dissection of atypical antipsychotic-induced weight gain: Novel preliminary data on the pharmacogenetic puzzle. J Clin Psychiatry 2001;62(Suppl 23):45-66.

146. Gunes A, Melkersson KI, Scordo MG, et al. Association between HTR2C and HTR2A polymorphisms and metabolic abnormalities in patients treated with olanzapine or clozapine. J Clin Psychopharmacol 2009;29:65-68.

147. Mulder H, Cohen D, Scheffer H, et al. HTR2C gene polymorphisms and the metabolic syndrome in patients with schizophrenia: A replication study. J Clin Psychopharmacol 2009;29:16-20.

148. Gregoor JG, Van Der Weide J, Mulder H, et al. Polymorphisms of the LEP- and LEPR gene and obesity in patients using antipsychotic medication. J Clin Psychopharmacol 2009;29: $21-25$.

149. Kwon JS, Joo YH, Nam HJ, et al. Association of the glutamate transporter gene SLCIAl with atypical antipsychotics-induced obsessive-compulsive symptoms. Arch Gen Psychiatry 2009;66:1233-1241

150. Volpi S, Potkin SG, Malhotra AK, et al. Applicability of a genetic signature for enhanced iloperidone efficacy in the treatment of schizophrenia. J Clin Psychiatry 2009;70:801-809.

151. Choi KH, Higgs BW, Weis S, et al. Effects of typical and atypical antipsychotic drugs on gene expression profiles in the liver of schizophrenia subjects. BMC Psychiatry 2009;9:57.

152. Chana G, Lucero G, Salaria S, et al. Upregulation of NRG-1 and VAMP-1 in human brain aggregates exposed to clozapine. Schizophr Res 2009;113:273-276.

153. Ji B, La Y, Gao L, et al. A comparative proteomics analysis of rat mitochondria from the cerebral cortex and hippocampus in response to antipsychotic medications. J Proteome Res 2009;8:3633-3641.

154. Ma D, Chan MK, Lockstone HE, et al. Antipsychotic treatment alters protein expression associated with presynaptic function and nervous system development in rat frontal cortex. $J$ Proteome Res 2009;8:3284-3297.

155. Dell'aversano C, Tomasetti C, Iasevoli F, et al. Antipsychotic and antidepressant co-treatment: Effects on transcripts of inducible postsynaptic density genes possibly implicated in behavioural disorders. Brain Res Bull 2009;79:123-129.

156. Lipska BK, Mitkus SN, Mathew SV, et al. Functional genomics in postmortem human brain: Abnormalities in a DISC1 molecular pathway in schizophrenia. Dialogues Clin Neurosi 2006;8:353-357.

157. Rastogi A, Zai C, Likhodi O, Kennedy JL, Wong AH. Genetic association and post-mortem brain mRNA analysis of DISCl and related genes in schizophrenia. Schizophr Res 2009;114:39-49.

158. Fleeman N, McLeod C, Bagust A, et al. The clinical effectiveness and cost-effectiveness of testing for cytochrome $\mathrm{P} 450$ polymorphisms in patients with schizophrenia treated with antipsychotics: A systematic review and economic evaluation. Health Technol Assess 2010;14:1-157, iii.

159. Schizophrenia Research Forum. Available from: www.szgene.org [Assessed 5 March 2010]

160. Kato T. Molecular genetics of bipolar disorder and depression. Psychiatry Clin Neurosci 2007;61:3-19.

161. Cacabelos R, editor. World guide for drug use and pharmacogenomics. Coruña, Spain: EuroEspes Publishing, 2010 (In Press).

162. Karolinska Institutet. Available from: www.cypalleles.ki.se [Assessed 5 March 2010]. 